\title{
EARLINET Single Calculus Chain - overview on methodology and strategy
}

\author{
G. D'Amico ${ }^{1}$, A. Amodeo ${ }^{1}$, H. Baars ${ }^{2}$, I. Binietoglou ${ }^{1,3}$, V. Freudenthaler ${ }^{4}$, I. Mattis ${ }^{2,5}$, U. Wandinger ${ }^{2}$, and \\ G. Pappalardo ${ }^{1}$ \\ ${ }^{1}$ Consiglio Nazionale delle Ricerche, Istituto di Metodologie per l'Analisi Ambientale (CNR-IMAA), Tito Scalo, \\ Potenza, Italy \\ ${ }^{2}$ Leibniz Institute for Tropospheric Research, Leipzig, Germany \\ ${ }^{3}$ National Institute of R\&D for Optoelectronics INOE, Bucharest, Romania \\ ${ }^{4}$ Ludwig-Maximilians-Universität, Meteorologisches Institut Experimentelle Meteorologie, Munich, Germany \\ ${ }^{5}$ Deutscher Wetterdienst, Meteorologisches Observatorium Hohenpeißenberg, Hohenpeißenberg, Germany
}

Correspondence to: G. D’Amico (giuseppe.damico@imaa.cnr.it)

Received: 20 March 2015 - Published in Atmos. Meas. Tech. Discuss.: 13 May 2015

Revised: 29 October 2015 - Accepted: 29 October 2015 - Published: 20 November 2015

\begin{abstract}
In this paper we describe the EARLINET Single Calculus Chain (SCC), a tool for the automatic analysis of lidar measurements. The development of this tool started in the framework of EARLINET-ASOS (European Aerosol Research Lidar Network - Advanced Sustainable Observation System); it was extended within ACTRIS (Aerosol, Clouds and Trace gases Research InfraStructure Network), and it is continuing within ACTRIS-2. The main idea was to develop a data processing chain that allows all EARLINET stations to retrieve, in a fully automatic way, the aerosol backscatter and extinction profiles starting from the raw lidar data of the lidar systems they operate. The calculus subsystem of the SCC is composed of two modules: a pre-processor module which handles the raw lidar data and corrects them for instrumental effects and an optical processing module for the retrieval of aerosol optical products from the pre-processed data. All input parameters needed to perform the lidar analysis are stored in a database to keep track of all changes which may occur for any EARLINET lidar system over the time. The two calculus modules are coordinated and synchronized by an additional module (daemon) which makes the whole analysis process fully automatic. The end user can interact with the SCC via a user-friendly web interface. All SCC modules are developed using open-source and freely available software packages. The final products retrieved by the SCC fulfill all requirements of the EARLINET quality assurance programs on both instrumental and algorithm levels. Moreover,
\end{abstract}

the manpower needed to provide aerosol optical products is greatly reduced and thus the near-real-time availability of lidar data is improved. The high-quality of the SCC products is proven by the good agreement between the SCC analysis, and the corresponding independent manual retrievals. Finally, the ability of the SCC to provide high-quality aerosol optical products is demonstrated for an EARLINET intense observation period.

\section{Introduction}

In general, the contribution of aerosols to atmospheric processes is not fully documented. In particular, an important gap needs to be filled to clarify the role of aerosols in the Earth radiation budget and in climate change (Intergovernmental Panel on Climate Change, 2007, 2013). The aerosols' high variability in terms of type, time and space makes it quite difficult to understand the atmospheric processes in which aerosols are involved (Diner et al., 2004). Therefore, there is a strong need from the scientific community to have access to comprehensive aerosol data sets in which vertically resolved aerosol optical parameters can be found. Lidar measurements, providing high-resolution profiles (in both space and time) of aerosol optical properties, meet this demand entirely as they allow the full characterization of each layer present in the atmosphere. 
Another important aspect for the study of aerosols on a planetary scale is the increased spatial coverage. To support this need, several coordinated lidar networks have been established in the last years (e.g., Bösenberg et al., 2008). In particular, EARLINET (European Aerosol Research Lidar Network) has been operated in Europe since the year 2000 and provides the scientific community with the most complete database of vertically resolved aerosol optical parameters across Europe (Pappalardo et al., 2014; The EARLINET publishing group 2000-2010, 2014). The EARLINET data can be used for several purposes including model evaluation and assimilation, full exploitation of satellite data, the study of aerosol long-range transport mechanisms, and the monitoring of special events like volcanic eruptions, large forest fires or dust outbreaks.

Within the EARLINET-ASOS (European Aerosol Research Lidar Network - Advanced Sustainable Observation System) project, great attention was paid to the optimization of lidar data processing (http://www.earlinetasos.org). The core of this activity was the development of the EARLINET Single Calculus Chain (SCC), a tool for the automatic evaluation of lidar data from raw signals up to the final products. The main advantage of this approach is that it increases the rate of population of the aerosol database (which is the main outcome of any lidar network) and to promote the usage of vertically resolved aerosol parameters within the scientific community.

This paper is the first of three publications about the SCC and it presents an overview of the SCC and its validation. Two separate papers are used to describe the technical details of the SCC pre-processing module (D'Amico et al., 2015) and of the optical processing module (Mattis et al., 2016), respectively.

A general overview of the SCC is provided in Sect. 2 of this paper. Section 3 illustrates the SCC structure by providing technical details of all SCC modules. The strategy adopted to validate the SCC is described in Sect. 4, and, finally, an example of the application of the SCC as a tool to provide network lidar data in near-real time is given in Sect. 5.

\section{SCC description}

The SCC is an official EARLINET tool. It has been developed to accomplish the fundamental need of any coordinated lidar network to have an optimized and automatic tool providing high-quality aerosol properties. Currently, it has been used by 20 different EARLINET stations which have submitted about 2600 raw data files covering a very large time period (2001-2015). Moreover, more than 5000 SCC optical products (about 3600 aerosol backscatter profiles and 1400 aerosol extinction profiles) have been calculated and used for different purposes like analysis of instrument intercomparisons (Wandinger et al., 2015), air-quality model assimilation experiment (Wang et al., 2014; Sicard et al., 2015), and ongoing long-term comparisons with manually retrieved products (Voudouri et al., 2015). The large usage and the long-term plan for the centralized processing system make the SCC the standard tool for the automatic analysis of EARLINET lidar data.

\subsection{General considerations}

Main concepts at the base of the SCC are automatization and fully traceability of quality-assured aerosol optical products. At network level, the SCC ensures high-quality products by implementing quality checks on both raw lidar data and final optical products. Such quality checks are part of a rigorous quality assurance program developed within EARLINET. In many specific situations, it is also quite important that the retrieved products are available in real time or in near-real time for large geographical areas (on a continental scale). For example, this is the case when vertically resolved lidar products are used to improve the forecast of air-quality models, to validate satellite sensors or models, or to monitor special events. Without a common analysis tool it could be difficult to assure at the same time homogenous high-quality products and short-time availability of the data, because high-quality manual lidar data analysis usually requires time and manpower. Moreover, different groups within the network may use different retrieval approaches to derive the same type of aerosol parameter with a consequent loss in the homogeneity of the network data set.

At the same time, in order to make the use of the SCC really sustainable, expandability and flexibility should be assured to guarantee the analysis of the data measured by new or upgraded lidar systems. Excluding few exceptions, a lidar network is usually formed by different and not standardized lidar systems ranging from single-wavelength elasticbackscatter lidar to advanced multi-wavelength Raman systems. A system is frequently improved or upgraded from a basic configuration to a more complex one by adding, for example, new detection channels. As a consequence, the SCC must be able to handle data acquired by different instruments which usually require different instrumental corrections and also different approaches to get quality-assured products. EARLINET is a good example showing how heterogenous the lidar systems forming a network can be. Most of the EARLINET lidar systems are home-made or highly customized, and typically they differ in terms of emitted or detected wavelengths, acquisition mode (analog and/or photon-counting), space and time resolution, and detection systems. A network like AERONET (Holben et al., 1998) does not suffer from this problem as it is based on the same standardized instrument. Therefore, a common scheme for the analysis of raw data does not need to take many different instrumental aspects into account and, thus, allows for reduced development complexity. 
In addition, the EARLINET quality assurance program on both instrumental (Matthias et al., 2004; Freudenthaler et al., 2016) and algorithm levels (Böckmann et al., 2004; Pappalardo et al., 2004) puts more constraints on the SCC development. In particular, it is required that each SCC product has been measured with a lidar system that passed the instrumental quality assurance tests, and it has been calculated applying certified algorithms.

With the SCC it is possible to calculate aerosol extinction and backscatter coefficient profiles. Especially in case of multi-wavelength lidar measurements, this set of optical parameters can provide a full characterization of atmospheric aerosol from both quantitative and qualitative point of view (Ackermann, 1998; Wandinger et al., 2002; Mattis et al., 2003; Müller et al., 2005). Moreover, these products can be used as input to infer microphysical properties of atmospheric particles (Müller et al., 1999a, b; Böckmann, 2001). It is important to stress that two independent SCC modules for the retrieval of microphysical properties of the atmospheric aerosols have been already developed (Müller et al., 2016). The main products of these modules are particle effective radius, volume concentration, and refractive index, which are calculated with a semi-automated and unsupervised algorithm. Although operational versions of these modules have been released, they are not included in the automatic structure of the SCC yet. Mainly, instability problems make the full automatization of lidar microphysical retrievals a quite challenging task.

The high flexibility and expandability of the SCC also makes it possible to use the tool in a more general context. As EARLINET already represents a quite complete example of all available lidar system types, it is expected to adapt the SCC easily to run in more extended networks like GALION (GAW Aerosol LIdar Observation Network).

To our knowledge, the SCC is the first tool that can be used to analyse raw data measured by many different types of lidar systems in a fully automatic way. Other existing automatic tools for the analysis of lidar data are usable only by specific lidar systems and cannot be easily extended to retrieve aerosol properties of whole lidar networks composed by different instruments. Another unique characteristic of the SCC is that its aerosol optical products are delivered according to a rigorous quality assurance program to provide always the highest possible quality for products at network level.

\subsection{Requirements}

In this section the requirements to accomplish all key points explained in the previous section are described. In the framework of the EARLINET quality assurance program several algorithms for the retrieval of aerosol optical parameters have been inter-compared to evaluate their performances in providing high-quality aerosol optical products (Böckmann et al., 2004; Pappalardo et al., 2004). This inter-comparison was mainly addressed to asses a common European standard for the quality assurance of lidar retrieval algorithms and to ensure that the data provided by each individual station are permanently of the highest possible quality according to common standards. All different quality-assured analysis algorithms developed within EARLINET have been collected, critically evaluated with respect to their general applicability, optimized to make them fully automatic, and finally implemented in the SCC. A critical point was the implementation of reliable and robust algorithms to assure accurate calibration of aerosol backscatter profiles. In a fully automatic analysis scenario, particular attention should be devoted to this issue to avoid large inaccuracy in the final optical products. Noisy raw lidar signals or the presence of aerosol within the calibration region can induce large errors in the lidar calibration constant (Klett, 1981, 1985).

The SCC has been developed having in mind the following concepts: platform independency, open-source philosophy, standard data format (NetCDF), flexibility through the implementation of different retrieval procedures, expandability to easily include new systems or new system configurations. All libraries and compilers needed to install and run the SCC are open source and freely available. The SCC can operate on a centralized server or on a local PC. The users can connect to the machine on which the SCC is running and use or configure the SCC retrieval procedures for their data using a web interface. The centralized server solution (which is the preferred way of using the tool) has many advantages compared to local installation, especially when the SCC is used within a coordinated lidar network as EARLINET. First of all, it is possible to keep track of all system configurations of all systems and also to certify which configurations are quality assured. Moreover, in this way it is always guaranteed that the same and latest SCC version is used to produce optical products.

Particular attention has been paid to the design of a suitable NetCDF structure for the SCC input file as it needs to fulfill the following constraints.

1. It should contain the raw lidar data as they are measured by the lidar detectors (output voltages for analog lidar channels, counts for photon-counting channels) without any correction earlier applied by the user. This is particularly important to assure the quality of the final products: all necessary instrumental corrections should be applied by the SCC using quality-assured procedures. For this reason a specific pre-processing SCC module has been developed.

2. It should contain additional input parameters needed for the analysis. As it will be explained in the next section, the main part of the required input parameters is efficiently stored in a SCC database. However, there are some parameters easily changing from measurement to measurement (e.g., electronic background or number of accumulated laser shots) that usually cannot be stored in a database. The only way to pass such parameters 
to the SCC is via the input file. To improve the selfconsistency of the SCC input file, it has been allowed to include in the file some important parameters already stored in the SCC database. In case these parameters are found in the input file these values will be used in the analysis.

3. It should also contain a unique method to link the information contained in the input file with the ones included in the SCC database. As it will be explained in the next section, this is assured by the definition of unique channel IDs which identify the different lidar channels.

4. It should allow efficient data processing. As the SCC has been designed to be a multi-user tool it is important to improve the computational speed as much as possible to avoid long delay in getting the final products. This has been accomplished by putting the time series of all channels available for a lidar configuration in a single SCC input file.

Finally, as the SCC products need to be uploaded to the EARLINET database, the output file structure is fully compliant with the structure of EARLINET $e$-files and $b$-files. The $e$-files contain the particle extinction coefficient profiles and optionally the backscatter coefficient profiles derived from Raman observations at the same effective vertical resolution. The $b$-files contain the particle backscatter coefficient profiles derived either from elastic-backscatter signals (Klett or iterative method) or from the ratio of elastic-backscatter and nitrogen Raman signals (Raman method) at highest possible vertical resolution. More details about EARLINET $e$ and $b$-files are provided elsewhere (Pappalardo et al., 2014; The EARLINET publishing group 2000-2010, 2014).

\section{SCC structure}

Figure 1 shows the general structure of the SCC which consists of several independent but inter-connected modules. Basically there is a module responsible for the pre-processing of raw lidar data, a module for the retrieval of the aerosol extinction and backscatter profiles, a daemon (computer program running as a background process without direct control of an interactive user) which automatically starts the preprocessing or the processing module when it is necessary, a database to collect all input parameters needed for the analysis, and finally a web interface. Once the new raw data file is submitted to the SCC via the web interface, the daemon automatically starts the pre-processing module and in succession the processing module. The status of the analysis in each step can be monitored using the web interface and the pre-processed or the optical results can be downloaded.

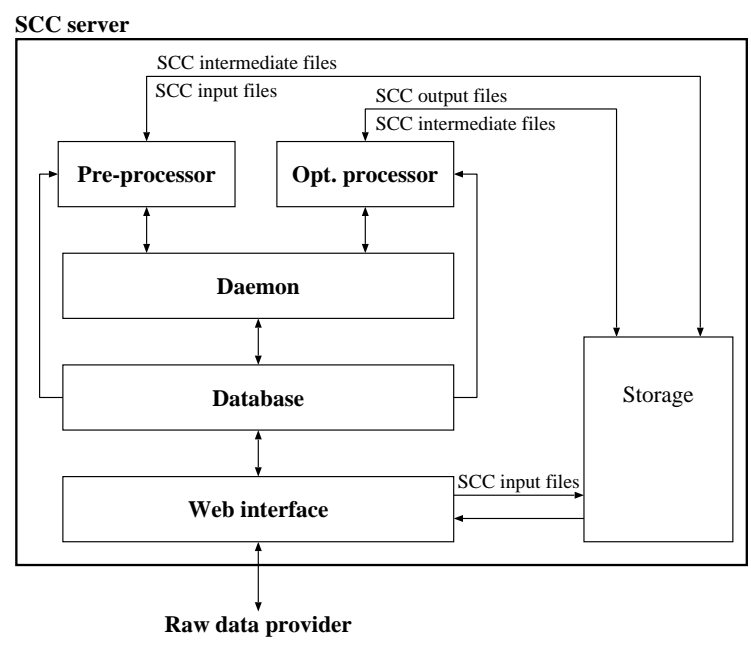

Figure 1. Block structure of the Single Calculus Chain.

\subsection{SCC database}

The retrievals of aerosol optical products from lidar signals require a large number of input parameters to be used in both pre-processing and processing phase. Two different types of parameters are needed: experimental (which are mainly used to correct instrumental effects) and configurational (which define the way to apply a particular analysis procedure). An example of experimental parameter is the dead time of a photon-counting system (Johnson et al., 1966; Whiteman et al., 1992). Once measured, the value of the dead time for a particular photon-counting lidar channel can be included in the database among the other parameters that characterize the channel and, consequently, it will be used to correct the corresponding raw lidar data. The dead time is an example of an experimental parameter that, in general, changes from channel to channel. There are other experimental parameters which may be shared by multiple channels, e.g., telescope or laser characteristics (several lidar channels usually share the same laser or the same telescope).

Configuration parameters are the ones used to identify which algorithm, among the implemented ones, has to be used to calculate a particular product. In general, there are multiple quality-assured algorithms in the SCC to calculate a particular aerosol product. For instance, for the particle backscatter coefficient profiles derived from elasticbackscatter signals both the iterative (Di Girolamo et al., 1995) and the Klett method (Klett, 1981, 1985; Fernald, 1984) have been implemented. The data provider can choose which one to use by setting a corresponding parameter in the database.

In general, both configuration and experimental parameters can change from one lidar system to another and, even for the same lidar system, they can change for the different configurations under which the lidar can run. For example, a lidar can deliver extinction and backscatter coefficient pro- 
files from Raman observations in night-time configuration, whereas elastic-backscatter methods are applied under daytime conditions.

In this complex context, a relational database represents an optimal solution to handle, in an efficient way, all this information. For this reason, a SCC database has been implemented to store the input parameters for all EARLINET systems and, at the same time, to access the subset of all parameters associated to a particular lidar configuration. A multipletable MySQL database has been used for that purpose.

In the SCC database, the experimental parameters are grouped in terms of stations, lidar configurations and lidar channels. Figure 2 shows a simplified version of the SCC database structure. Each station is linked to one or more lidar configurations which in turn are linked to one or more lidar channels. Moreover, each lidar configuration is associated also to a set of products that the SCC should calculate. Basically, the products are specified in terms of type (e.g., aerosol extinction, backscatter by Raman method, etc.) and "usecase" which, as it will be explained later, represents the way to calculate the product. Additionally, for a particular product, it is possible to fix a set of calculation options, e.g., the pre-processing vertical resolution, the backscatter calibration method, the maximum statistical error we would like to have on the final products and so on.

Finally, when lidar measurement sessions are submitted to the SCC they are linked to a specific lidar configuration. In this way, with specific SCC database queries, it is possible to get any detail needed for the analysis of the lidar measurements.

On one hand, a so structured database allows us to keep track of all information used to generate a particular SCC product assuring the full traceability; on the other hand, it guarantees the implementation of a reliable and rigorous quality assurance program at network level.

\subsection{Pre-processor module (ELPP: EARLINET Lidar Pre-Processor)}

The ELPP module implements the corrections to be applied to the raw lidar signals before they can be used to derive aerosol optical properties. As the details of this module are described in D'Amico et al. (2015) here just the main characteristics are reported.

The main reason for which we implemented a preprocessor module along with a optical processing module is that the EARLINET quality assurance program does not apply only to the retrieval of aerosol optical properties but also to the procedures needed to correct instrumental effects. Moreover, by handling the raw data it is possible to identify problems in lidar signals that may be not so evident in already pre-processed signals. The raw lidar signals have to be submitted in a NetCDF format with a well-defined structure (D'Amico et al., 2015). In particular, the raw lidar data should consist of the signal as detected by the lidar detec-

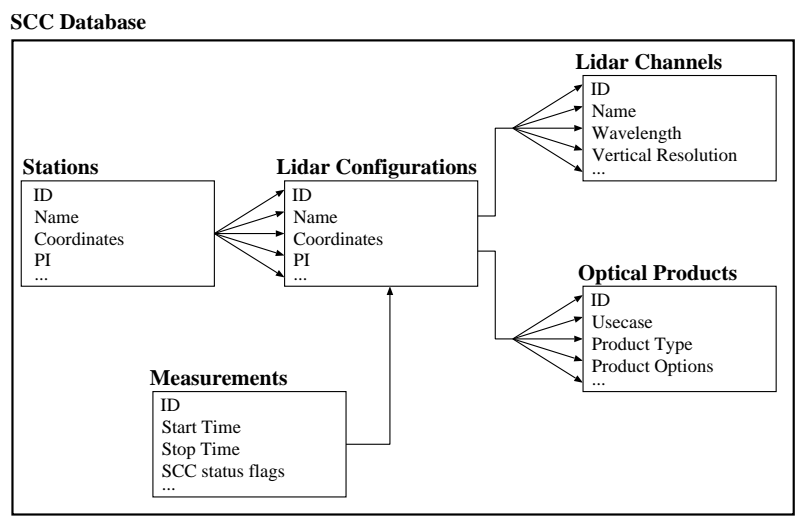

Figure 2. Simplified version of the SCC database structure. Multiple arrows indicate one-to-many relationship while single arrows represent one-to-one correspondence.

tors. In case of analog detection mode the signal should be provided in $\mathrm{mV}$, while for photon-counting mode it should be expressed in pure counts. According to the specific lidar system and to the input parameters defined both in the SCC database and in the NetCDF input file, different types of operations can be applied on raw data. To make the SCC a useful tool for all EARLINET systems it is required that the pre-processing module implements all different instrumental corrections defined for the different EARLINET lidars. The complete description of all these corrections is given in D'Amico et al. (2015), here we just report a list of the most common ones: dead-time correction, trigger-delay correction, overlap correction, background subtraction (both atmospheric and electronic). Besides these corrections, the pre-processor module is also responsible for generating the molecular signal needed to calculate the aerosol optical products. This can be done by using a standard model atmosphere (e.g., US 1976) or correlative radiosounding profiles. Finally, the pre-processor module implements near- and far-range automatic signal gluing, vertical interpolation, time averaging and statistical uncertainty propagation (Amodeo et al., 2016). The outputs of the pre-processor module are intermediate pre-processed NetCDF files which will be the input files for the optical processor module. These files contain the pre-processed range-corrected lidar signals, the statistical uncertainties, and the corresponding molecular atmospheric profiles. As these quantities can be used in many different fields of application (quick-look generation, model assimilation, inter-comparison campaigns) the intermediate NetCDF files can be considered additional (non-calibrated) products provided by the SCC.

\subsection{Optical processor module (ELDA: EARLINET Lidar Data Analyzer)}

The ELDA module applies the algorithms for the retrieval of aerosol optical parameters to the pre-processed signals pro- 

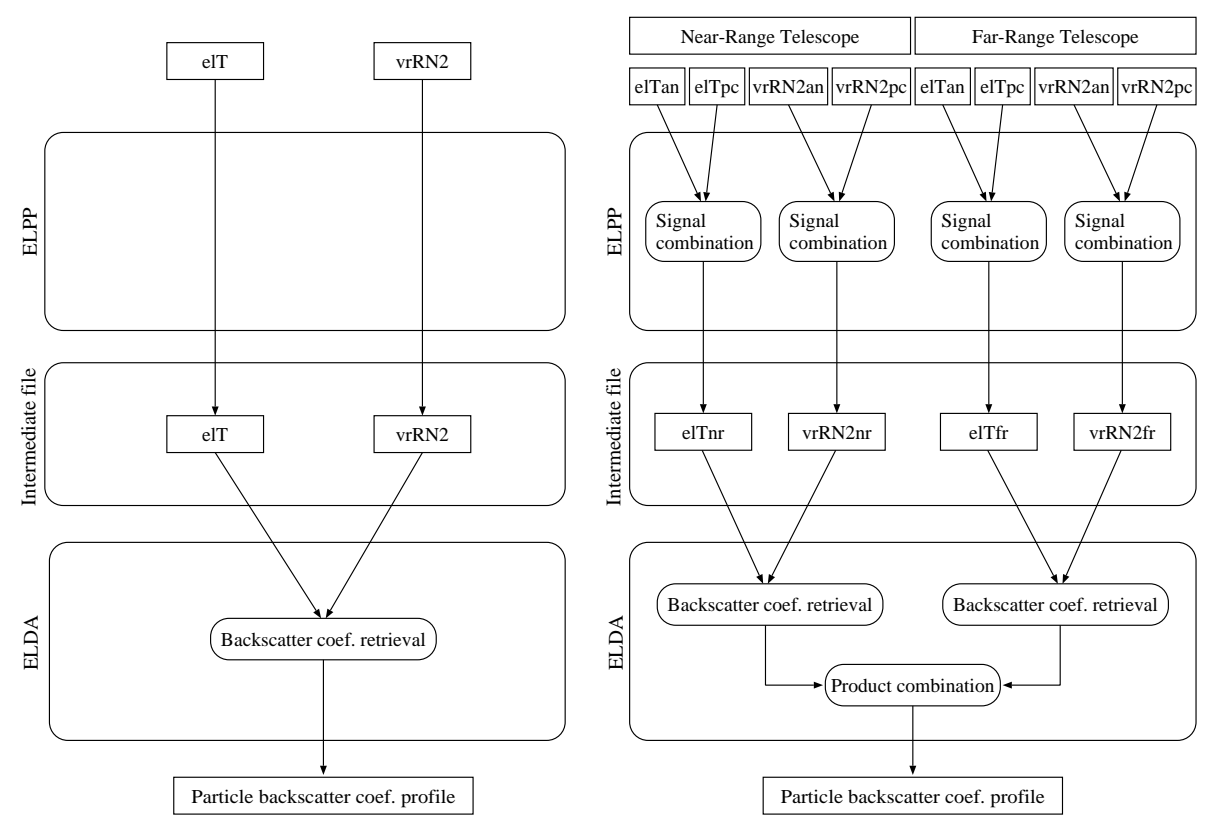

Figure 3. Two examples of SCC usecases corresponding to the calculation of particle backscatter coefficient determined by the use of Raman signals. In particular, the usecase 0 (on the left) can be used for a lidar system measuring only the elastic backscattered signal (elT) and the corresponding $\mathrm{N}_{2}$ Raman backscattered signal (vrRN2). The usecase 13 (on the right) refers to a more complex lidar configuration in which there are two different telescopes. Four lidar channels are detected by each telescope: one elastic backscattered signal split in analog (elTan) and photon-counting (elTpc) detection channels and one $\mathrm{N}_{2}$ Raman backscattered signal split in analog (vrRN2an) and photon-counting (vrRN2pc) detection mode.

duced by the pre-processor module. All details of the ELDA module are described in Mattis et al. (2016), therefore only a very brief overview of its main functionalities is given here. ELDA can provide aerosol products in a flexible way choosing from a set of possible pre-defined analysis procedures (usecases). ELDA enables the retrieval of particle backscatter coefficients by using both the Klett method (Klett, 1981; Fernald, 1984) and the iterative algorithm (Di Girolamo et al., 1995), the calculation of particle extinction coefficient profiles after the Raman method (Ansmann et al., 1990; Papayannis et al., 1990), and finally the computation of particle backscatter coefficient profiles after the Raman method (Ansmann et al., 1992). An automatic vertical-smoothing and time-averaging technique selects the optimal resolution as a function of altitude on the basis of different thresholds on product uncertainties fixed in the SCC database for each product (Mattis et al., 2016). The final optical products are written in NetCDF files with a structure fully compliant with the EARLINET $e$-files and $b$-files.

\subsection{Usecase}

To improve the flexibility of the SCC, the concept of "usecase" has been introduced. The SCC utilizes the usecases to adapt the analysis of lidar signals to a specific lidar configuration. Each usecase identifies a particular way to han- dle lidar data. An example on how the usecases are defined is illustrated in Fig. 3. In the left part of the figure usecase 0 for the calculation of the backscatter coefficient after the Raman method is schematically shown. This usecase refers to a basic Raman lidar configuration where only an elastic signal (elT) and the corresponding vibrationalrotational $\mathrm{N}_{2}$ Raman signal (vrRN2) are detected. These two signals are pre-processed by the SCC pre-processor module and the results are saved in a NetCDF intermediate file. Then ELDA ingests the preprocessed signals and delivers the particle backscatter coefficient profile as final result. In the right part of Fig. 3 a more complex usecase (the usecase 13) for aerosol backscatter calculations after the Raman method is reported. It corresponds to a lidar system that uses two different telescopes: one optimized to detect the signal backscattered by the near-range atmospheric region and another one optimized to detect the atmospheric signal from the far range. Moreover, for both telescopes the elastic and the vibrational-rotational $\mathrm{N}_{2}$ Raman signals are detected in ana$\log$ and photon-counting mode. In this case, the SCC should combine eight raw signals to get a unique particle backscatter coefficient profile. Looking at Fig. 3 we can see the details of this combination for the usecase 13. First, the analog and the corresponding photon-counting signals are combined by the pre-processor module. This step results in four signals being reported in the intermediate NetCDF file. These signals cor- 
respond to the combined (analog and photon-counting) elastic and vibrational-rotational $\mathrm{N}_{2}$ Raman signals detected by the near-range and far-range telescopes. The ELDA module combines these four pre-processed signals and retrieves two different backscatter coefficient profiles (one for the nearrange and the other for the far-range). Finally, these products are glued together to get a single particle backscatter coefficient profile.

A total of 34 different usecases have been defined and implemented within the SCC for the calculation of all optical products. A schematic description of all implemented usecases is provided in the Appendix. This set of usecases assures that all different EARLINET lidar setups can be processed by the SCC. Moreover, we may have further flexibility choosing among the different usecases compatible for a fixed lidar configuration.

Finally, the concept of usecase improves also the expandability of the SCC: to implement a new lidar configuration in the SCC it is sufficient to implement a new usecase, if the ones already defined are not compatible with it.

\subsection{SCC daemon module}

The SCC database, the ELPP and ELDA modules are well separated objects that need to act in a coordinated and synchronized way. When a set of raw lidar data is submitted to the SCC a new entry is created in the SCC database. As soon as this operation is completed, the pre-processing module should be started to treat the submitted measurements. As soon as there are pre-processed data available, the ELDA module should be started to retrieve the aerosol optical products. All of these operations are performed by the module SCC daemon. This module is a multithread process running continuously in the background, and it is responsible to start thread instances for the pre-processor or the optical processor module when it is necessary. Another important function of the SCC daemon is to monitor the status of started modules and to track the corresponding exit status in the SCC database.

As the SCC is mainly designed to run on a single server where multiple users can perform different lidar analyses at the same time, the SCC daemon has been developed to act in a multithread environment. In this way, different processes can be started in parallel by the SCC daemon enhancing the efficiency of the whole SCC.

\subsection{Web interface}

This module represents the interface between the raw data provider and the SCC. In particular, the SCC end-user needs to interact only with the SCC database because, as already mentioned, all other analysis procedures are handled by the SCC daemon automatically. The web interface provides a user-friendly way to interact with the SCC database by us- ing any of available web browsers. Via the web interface it is possible to do the following:

1. change or visualize all input parameters for a particular lidar system or add a new system;

2. upload data to the SCC server and register the measurements in the SCC database. Along with the raw lidar data it is also possible to upload ancillary files, e.g., correlative sounding profiles and overlap correction functions which can be used in the analysis. All of these files should be in NetCDF format with a well-defined structure. The interface does not allow the upload of files that are in wrong format or not compliant with the defined structure;

3. visualize the status of the SCC analysis. In case of failure a specific error message is shown so that the user can easily figure out the reason for the failure;

4. download the pre-processed or the optical processed data from the server. In particular, it is possible to visualize the calculated profiles of aerosol optical products;

5. re-apply the SCC on an already analysed measurement.

The web interface has been developed in a way that the above actions can be performed depending on different types of accounts. For instance, users belonging to a particular lidar station cannot modify any input parameters for a lidar system linked to a different lidar station. It is also possible, e.g., to define users that can only perform analysis and cannot change input parameters.

Moreover, the processing status of each measurement can be also monitored using a web API (application programming interface). Using this API, the SCC can be tightly integrated to each station processing system making the process of submission of the raw data and the corresponding analysis fully automatic.

Finally, using the web interface it is possible to have access to the EARLINET Handbook of Instrumentation (HOI) where all instrumental characteristics of the lidar systems registered in the SCC database are reported. The main goal of the HOI is to collect all characteristics of all EARLINET lidar systems and to make this information available for the end-user in an efficient and user-friendly way. For this reason, the information in the HOI is grouped in terms of different subsystems composing a complete lidar system: laser source, telescope, spectral separation, acquisition system. Additional information concerning the station running the lidar system is also provided, including a history of any changes made to the lidar in question.

\section{Validation}

A validation strategy to prove whether the SCC can provide quality-assured aerosol optical products has been im- 

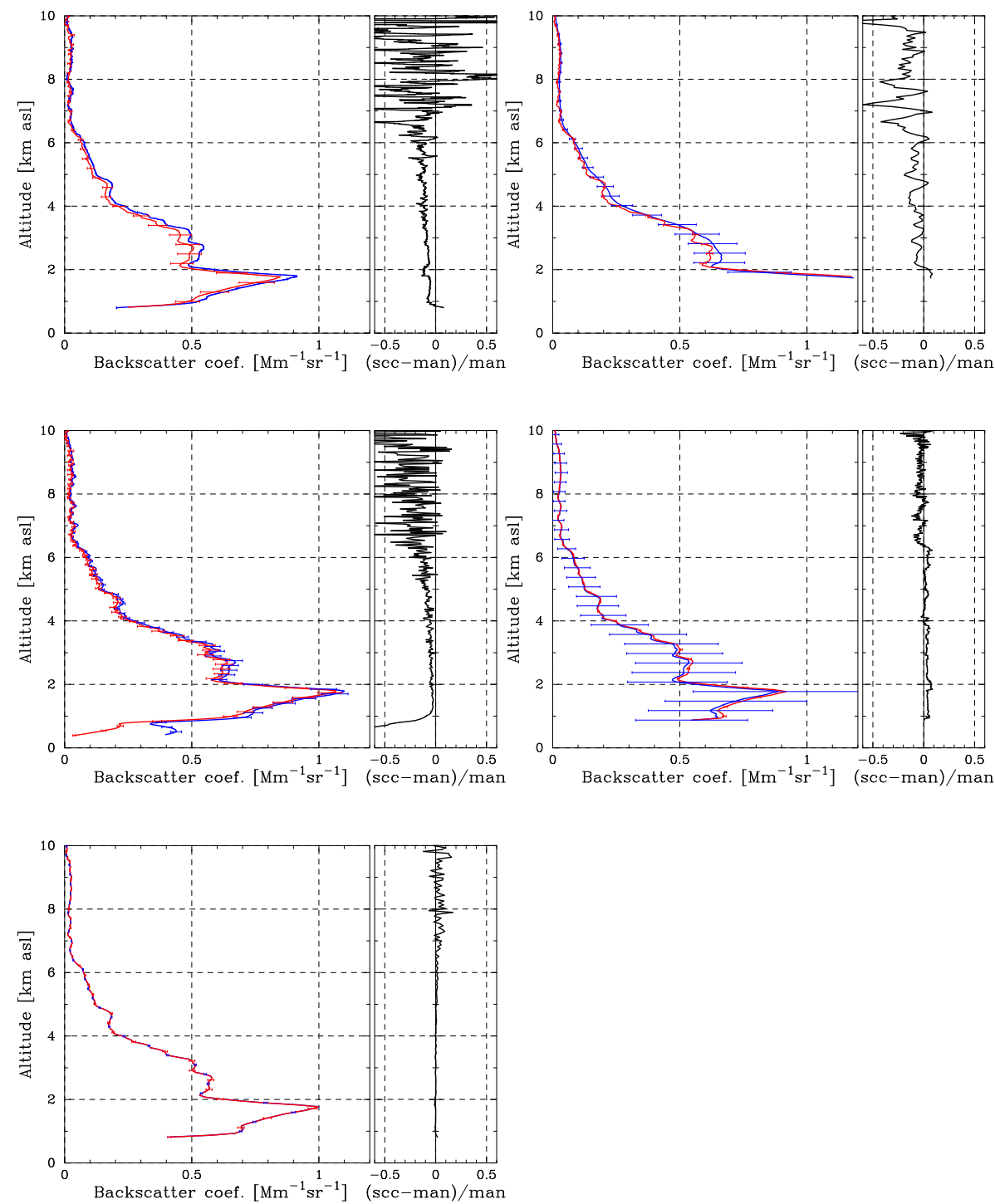

Figure 4. Comparison of backscatter coefficient profiles at $1064 \mathrm{~nm}$ derived with the iterative method for five lidar systems participating in the EARLI09 inter-comparison campaign. All profiles refer to the measurement session taken from 21:00 to 23:00 UT on 25 May 2009. The profiles in blue are the analyses provided by the originator of the data using his/her own analysis software. The profiles in red are the ones retrieved by the SCC. From left to right, upper panel: RALI, MARTHA; middle panel: Polly XT, MSTL-2; bottom panel: MUSA.

plemented. The performance of the SCC has been evaluated on both synthetic and real lidar data.

As a first step, the SCC has been tested with synthetic lidar signals used during the algorithm inter-comparison exercise performed in the framework of the EARLINET project (Pappalardo et al., 2004). This set of synthetic signals was simulated with really realistic experimental and atmospheric conditions to test the performance of specific algorithms for the retrieval of particle extinction and backscatter coefficient profile. By comparing the calculated profiles with the corresponding input profiles used to simulate the signals it is possible to verify, if an implemented algorithm returns reliable results. As the details of this exercise are provided in Mattis et al. (2016) we just mention here that all algorithms implemented within the SCC produce profiles that agree with the solutions within the statistical uncertainties.

As second validation level, we have evaluated the SCC performance when it is applied to real lidar data by comparing the optical products calculated by the SCC with the corresponding optical products generated by the analysis software developed by different EARLINET lidar groups and used so far to provide lidar profiles to the EARLINET database. This comparison has been performed using two different approaches. First, we compared the analysis for lidar measurements taken by several lidar systems at the same place and at the same time as in the case of the EARLI09 (EArlinet Refer- 

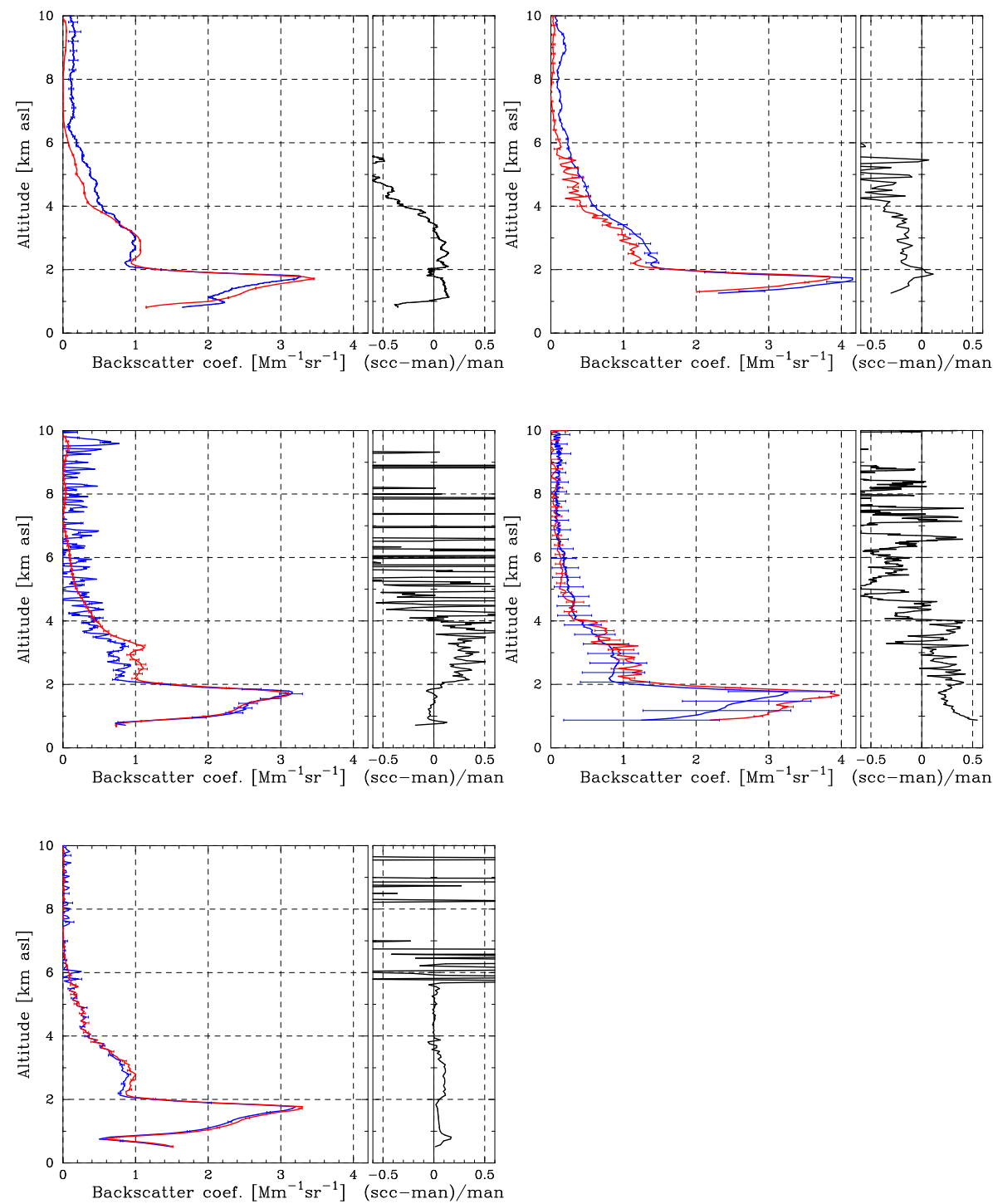

Figure 5. Comparison of backscatter coefficient profiles at $355 \mathrm{~nm}$ derived with the Raman method for five lidar systems participating in the EARLI09 inter-comparison campaign. All profiles refer to the measurement session taken from 21:00 to 23:00 UT on 25 May 2009, and they have been retrieved combining elastic-backscatter signals at $355 \mathrm{~nm}$ and the corresponding $\mathrm{N}_{2}$ Raman backscatter signals at $387 \mathrm{~nm}$. The profiles in blue are the analyses provided by the originator of the data using his/her own analysis software. The profiles in red are the ones retrieved by the SCC. From left to right, upper panel: RALI, MARTHA; middle panel: Polly XT, MSTL-2; bottom panel: MUSA.

ence Lidar Intercomparison 2009) campaign (Freudenthaler et al., 2010; Wandinger et al., 2015). Secondly, we have used climatological data of two EARLINET stations to evaluate possible biases in the SCC analysis not visible from the comparison of one single case.

\subsection{Validation based on EARLI09 data}

The EARLI09 measurement campaign held in Leipzig, Germany, in May 2009 gave us the possibility to test the SCC with measurements taken by different lidar systems under the same atmospheric conditions. Eleven lidar systems from ten different EARLINET stations performed one month of co-located, coordinated measurements under different meteorological conditions. During the campaign, the SCC preprocessor module was successfully used to provide, in a very short time, signals corrected for instrumental effects for all participating lidar systems (Wandinger et al., 2015). In this way, all signals were pre-processed with the same procedures and, consequently, discrepancies among pre-processed signals could be only due to unknown system effects.

The data set of the EARLI09 campaign gives us a good opportunity to test not only the pre-processor module but also all other SCC modules. After the campaign, a few cases were selected which were characterized by data availability from 

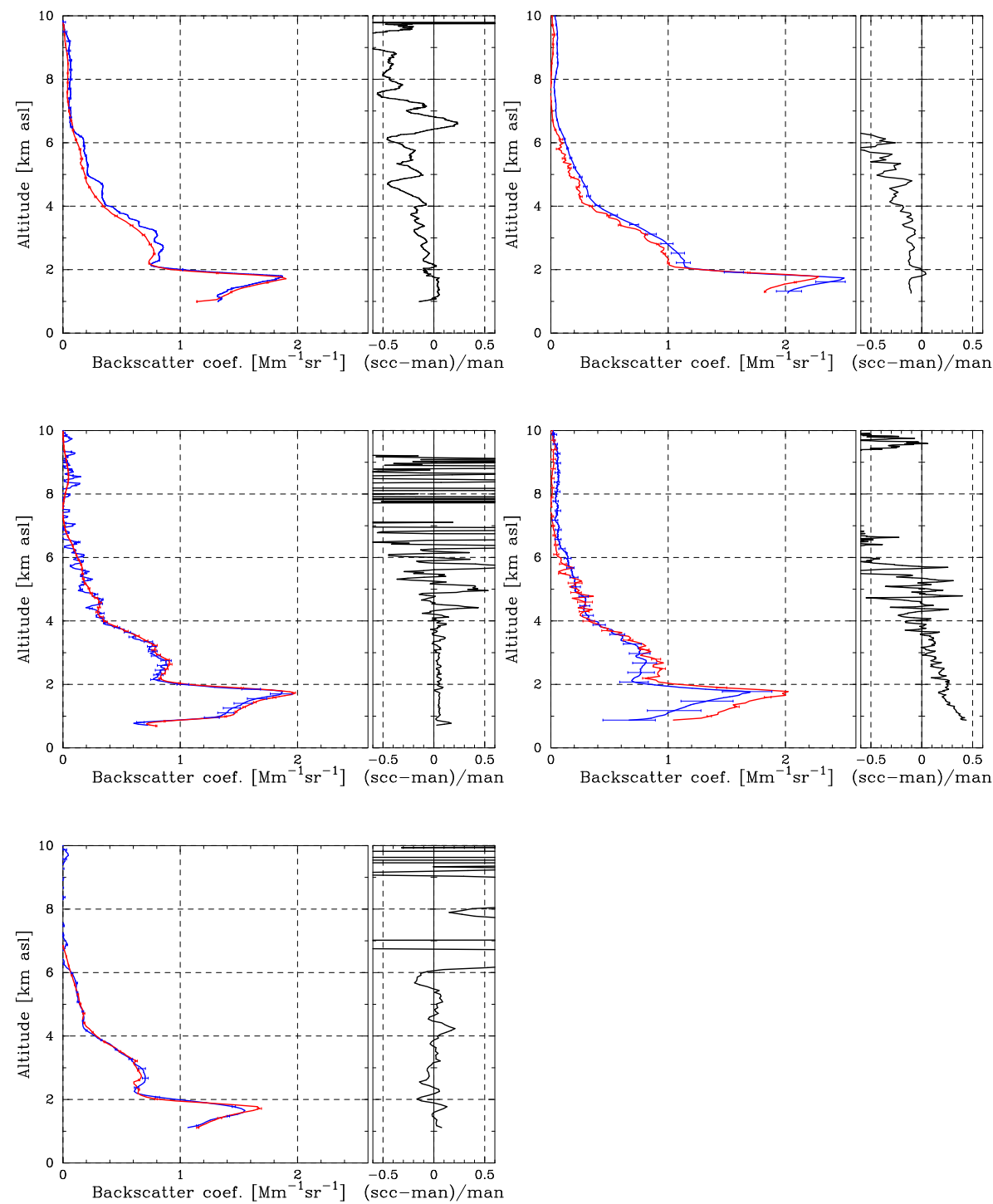

Figure 6. Comparison of backscatter coefficient profiles at $532 \mathrm{~nm}$ derived with the Raman method for five lidar systems participating in the EARLI09 inter-comparison campaign. All profiles refer to the measurement session taken from 21:00 to 23:00 UT on 25 May 2009, and they have been retrieved combining elastic-backscatter signals at $532 \mathrm{~nm}$ and the corresponding $\mathrm{N}_{2}$ Raman backscatter signals at $607 \mathrm{~nm}$. The profiles in blue are the analyses provided by the originator of the data using his/her own analysis software. The profiles in red are the ones retrieved by the SCC. From left to right, upper panel: RALI, MARTHA; middle panel: Polly XT, MSTL-2; bottom panel: MUSA.

all participating systems and stable atmospheric conditions. All participants were asked to produce their own analysis for these cases allowing us to compare these profiles with the corresponding results of the SCC. The cases differ in terms of atmospheric conditions and refer to both night-time and daytime measurements.

For the SCC validation we focus on the case of 25 May 2009 from 21:00 to 23:00 UT when a Saharan dust event occurred over Leipzig. To allow for a complete evaluation of the SCC retrieval algorithms, we first selected only the EARLI09 lidar systems able to measure at same time backscatter coefficient profiles at three wavelengths (1064, 532 and $355 \mathrm{~nm}$ ) and extinction coefficient profiles at 532 and $355 \mathrm{~nm}$. Among these advanced systems, we made a further selection on the basis of their differences in terms of technical characteristics. In particular, we considered the Multiwavelength Raman Lidar (RALI) from Bucharest (Nemuc et al., 2013) as an example of a commercial lidar system; the MARTHA (Multiwavelength Atmospheric Raman Lidar for Temperature, Humidity, and Aerosol Profiling) system from Leipzig as an example of a home-made lidar (Mattis et al., 2004); the Polly ${ }^{\mathrm{XT}}$ from Leipzig as representative of the Polly ${ }^{\mathrm{Net}}$ network (Althausen et al., 2013); the CIS-LiNet (Lidar Network for Commonwealth of Independent States countries, 

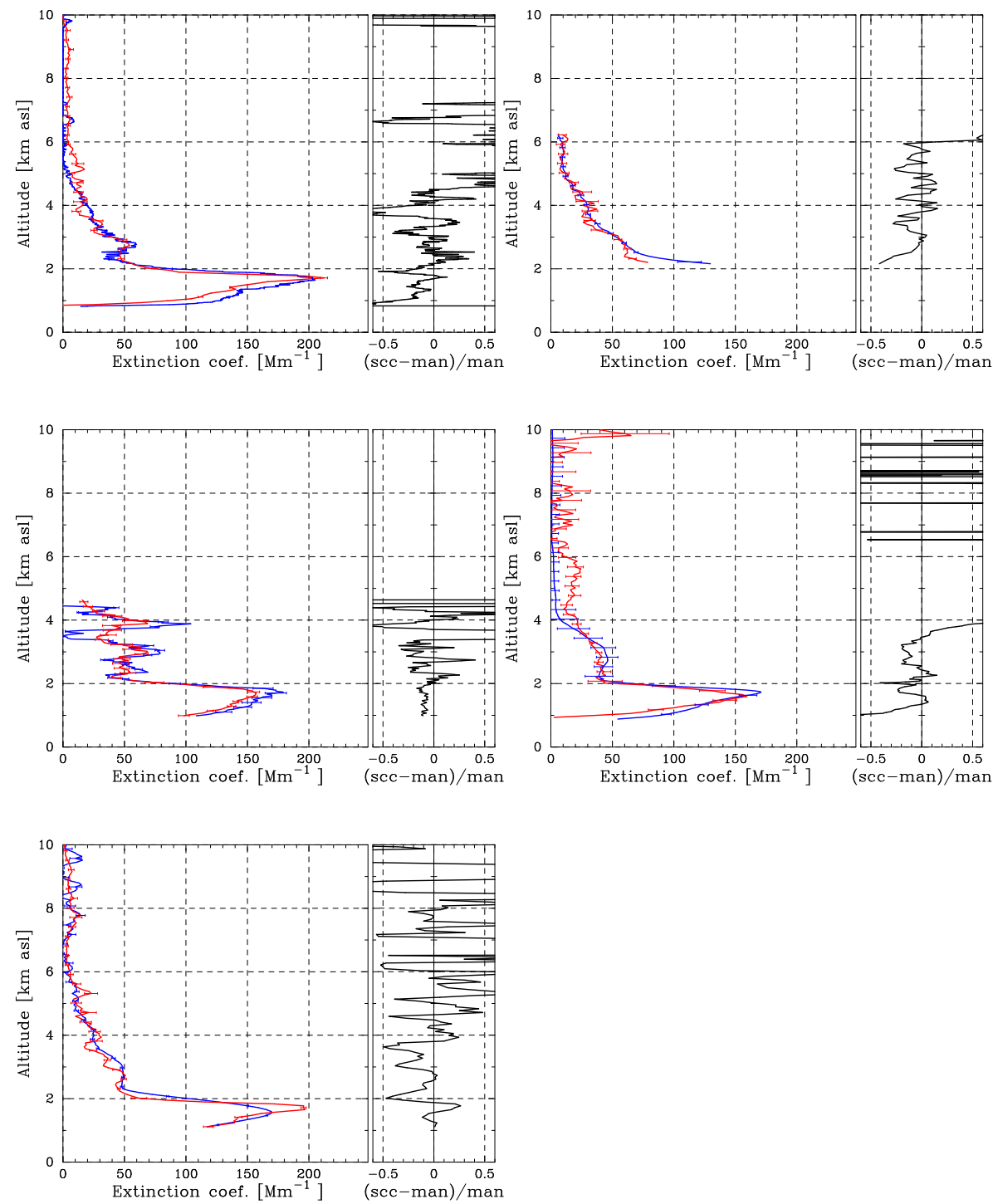

Figure 7. Comparison of extinction coefficient profiles at $355 \mathrm{~nm}$ derived with the Raman method for five lidar systems participating in the EARLI09 inter-comparison campaign. All profiles refer to the measurement session taken from 21:00 to 23:00 UT on 25 May 2009, and they have been retrieved using the $\mathrm{N}_{2}$ Raman backscatter signals at $387 \mathrm{~nm}$. The profiles in blue are the analyses provided by the originator of the data using his/her own analysis software. The profiles in red are the ones retrieved by the SCC. From left to right, upper panel: RALI, MARTHA; middle panel: PollyXT, MSTL-2; bottom panel: MUSA.

Chaikovsky et al., 2006) reference system MSTL-2 from Minsk and, finally, the MUSA (Multiwavelength System for Aerosol) from Potenza as an EARLINET network reference system (Madonna et al., 2011).

Figure 4 shows the backscatter coefficient profiles at $1064 \mathrm{~nm}$ obtained from the elastic-backscatter signals measured by the five lidar systems mentioned above. The profiles obtained by the SCC are plotted in red, while the corresponding profiles provided by each group with its own analysis software are shown in blue. The same colour convention is valid for all other figures in this paper. The agreement between the two analyses is generally good for all lidar systems indicating the good performance of the algorithm for the retrieval of the aerosol backscatter coefficient from elasticbackscatter signals implemented in the SCC. The red profiles shown in Fig. 4 are obtained using the iterative method. However, we found that the SCC profiles obtained using the Klett approach are practically indistinguishable from the ones calculated by the iterative technique.

A more quantitative comparison between SCC and manual retrievals can be performed by calculating the mean deviation $\bar{d}$ and the mean relative deviation $\bar{d}_{\mathrm{r}}$ defined as

$\bar{d}=\left\langle s_{i}-m_{i}\right\rangle$, 

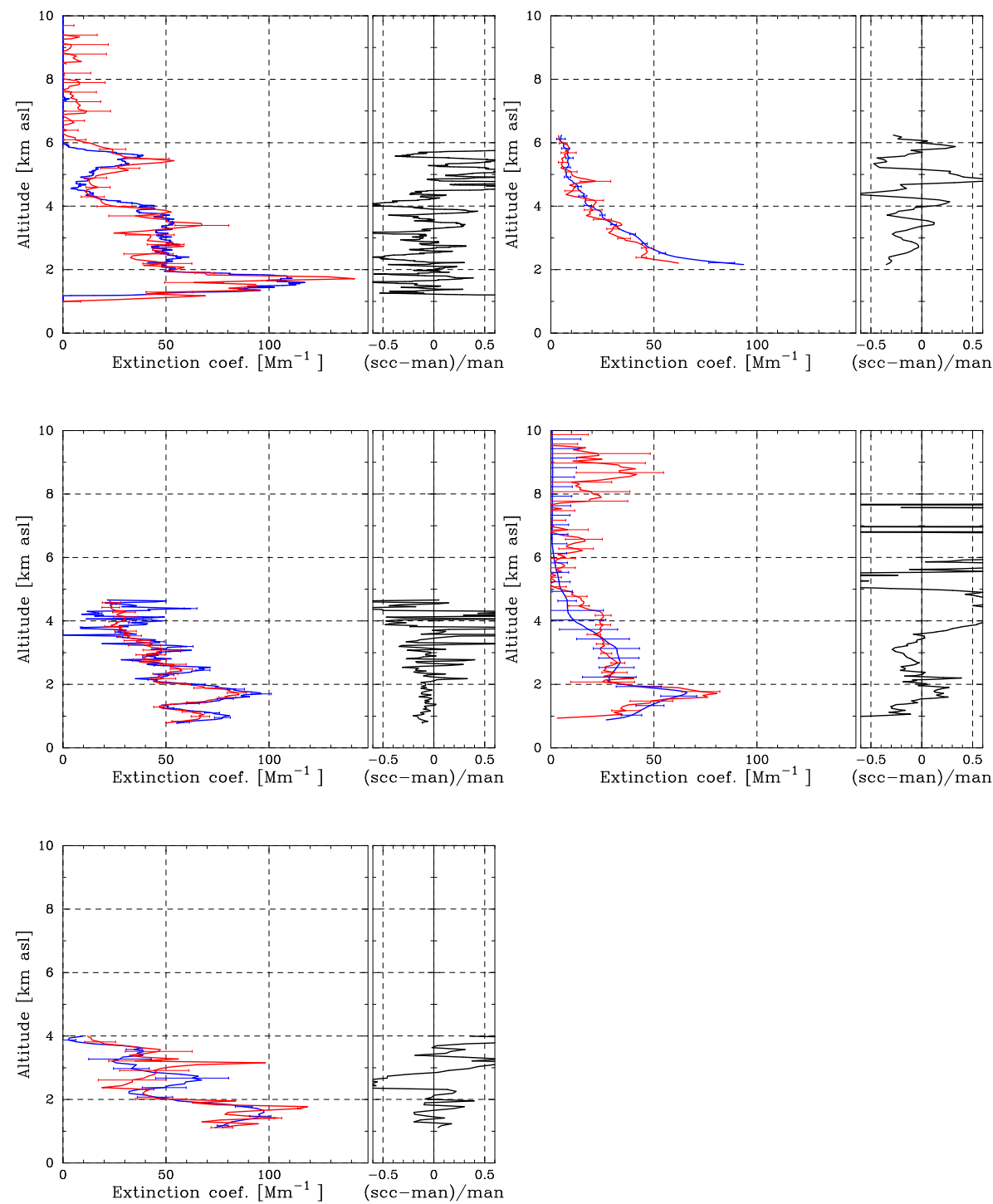

Figure 8. Comparison of extinction coefficient profiles at $532 \mathrm{~nm}$ derived with the Raman method for five lidar systems participating in the EARLI09 inter-comparison campaign. All profiles refer to the measurement session taken from 21:00 to 23:00 UT on 25 May 2009, and they have been retrieved using the $\mathrm{N}_{2}$ Raman backscatter signals at $607 \mathrm{~nm}$. The profiles in blue are the analyses provided by the originator of the data using his/her own analysis software. The profiles in red are the ones retrieved by the SCC. From left to right, upper panel: RALI, MARTHA; middle panel: PollyXT, MSTL-2, bottom panel: MUSA.

$\bar{d}_{\mathrm{r}}=\left\langle\frac{s_{i}-m_{i}}{m_{i}}\right\rangle$,

where $s_{i}$ and $m_{i}$ are the values of the SCC and the manually retrieved profile at altitude bin $i$, respectively. The symbol $\langle\cdot\rangle$ refers to the average over the altitude scale.

The values obtained for the parameters $\bar{d}$ and $\bar{d}_{\mathrm{r}}$ starting from the profiles shown in Fig. 4 are summarized in the last two columns of Table 1. For the backscatter retrieval at $1064 \mathrm{~nm}$, the mean relative deviations range from a maximum underestimation of $-10.5 \%$ for the RALI system to a maximum overestimation of $4.4 \%$ for the MSTL-2 system.
The EARLINET quality requirements allow a maximum deviation of $30 \%$ or $0.5 \mathrm{Mm}^{-1} \mathrm{sr}^{-1}$ for the backscatter coefficient at $1064 \mathrm{~nm}$ (Matthias et al., 2004). Consequently, the SCC backscatter coefficient retrieval at $1064 \mathrm{~nm}$ meets the EARLINET quality requirements for both $\bar{d}$ and $\bar{d}_{\mathrm{r}}$ for all the considered systems. The highest relative mean deviation observed for the RALI system is probably due to slightly different calibration input parameters used in the two analyses as the infrared wavelength is quite sensible to the calibration procedure (Engelmann et al., 2016).

The backscatter coefficient profiles at $355 \mathrm{~nm}$ (at $532 \mathrm{~nm}$ ) derived with the Raman method from the same lidar sys- 
Table 1. Absolute $(\bar{d})$ and relative $\left(\bar{d}_{\mathrm{r}}\right)$ mean deviations between SCC and corresponding manual analysis. The parameters $\bar{d}$ and $\bar{d}_{\mathrm{r}}$ are calculated according to the Eqs. (1) and (2), respectively, and considering all the profile altitude bins shown in Figs. 4-8. Backscatter coefficient absolute differences are expressed in $\mathrm{Mm}^{-1} \mathrm{sr}^{-1}$, while extinction coefficient absolute differences are given in $\mathrm{Mm}^{-1}$.

\begin{tabular}{|c|c|c|c|c|c|c|}
\hline \multirow[b]{2}{*}{ System } & \multicolumn{2}{|c|}{$355 \mathrm{~nm}$} & \multicolumn{2}{|c|}{$532 \mathrm{~nm}$} & \multicolumn{2}{|c|}{$1064 \mathrm{~nm}$} \\
\hline & $\bar{d}$ & $\bar{d}_{\mathrm{r}}[\%]$ & $\bar{d}$ & $\bar{d}_{\mathrm{r}}[\%]$ & $\bar{d}$ & $\bar{d}_{\mathrm{r}}[\%]$ \\
\hline & \multicolumn{6}{|c|}{ Backscatter coefficient } \\
\hline RALI & -0.065 & -10.3 & -0.040 & -9.3 & -0.024 & -10.5 \\
\hline MARTHA & -0.146 & -20.9 & -0.028 & -6.0 & -0.012 & -5.9 \\
\hline Polly XT & 0.037 & 6.9 & -0.008 & -1.9 & -0.027 & -9.5 \\
\hline MSTL-2 & 0.080 & 14.6 & 0.068 & 18.2 & 0.010 & 4.4 \\
\hline \multirow[t]{2}{*}{ MUSA } & 0.025 & 3.7 & 0.008 & 1.7 & -0.005 & -2.0 \\
\hline & \multicolumn{6}{|c|}{ Extinction coefficient } \\
\hline RALI & -3.162 & -6.3 & 1.362 & 3.3 & & \\
\hline MARTHA & -0.511 & -1.5 & -1.172 & -4.5 & & \\
\hline Polly XT & -6.754 & -9.5 & -6.002 & -11.9 & & \\
\hline MSTL-2 & 4.126 & 17.6 & 1.511 & 6.5 & & \\
\hline MUSA & -0.574 & -2.1 & 1.571 & 3.0 & & \\
\hline
\end{tabular}

tems are shown in Fig. 5 (Fig. 6). The manually obtained profiles agree quite well with the corresponding SCC ones, considering the reported error bars. As shown in Table 1, for all systems the mean deviations are larger at $355 \mathrm{~nm}$ than at $532 \mathrm{~nm}$. In particular, at $355 \mathrm{~nm}$ the relative mean deviation ranges from -20.9 to $14.6 \%$, while at $532 \mathrm{~nm}$ the range is from -9.3 to $18.2 \%$. According to the EARLINET requirements deviations of aerosol backscatter coefficients at 355 and $532 \mathrm{~nm}$ have to be below $20 \%$ or smaller than $0.5 \mathrm{Mm}^{-1} \mathrm{sr}^{-1}$ (Matthias et al., 2004). The EARLINET requirements on $\bar{d}_{\mathrm{r}}$ and $\bar{d}$ are met at both wavelengths by the majority of the systems. The only exception is the MARTHA system for which the SCC retrieval shows a relative mean deviation slightly above the maximum. However, at the same time, the EARLINET requirements on $\bar{d}$ are clearly below the maximum allowed value for all the systems. In general, the discrepancies can be explained by small differences in the reference value and in the height range used for the calibration and also by the depolarization correction (Mattis et al., 2009), which is taken into account in some of the manual analyses but not implemented yet in the SCC. This is, for example, the reason for the discrepancies observed between 2 and $4 \mathrm{~km}$ in the backscatter profiles at $355 \mathrm{~nm}$ for Polly XT (leftmost plot in the middle panel of Fig. 5). This lidar system is equipped with optics exhibiting quite different transmissivity at $355 \mathrm{~nm}$ for the two components of light polarization. In this case, if the depolarization correction is not considered and, at same time, strong depolarizing aerosol is observed (like in this case where Saharan dust was present between 2 and $4 \mathrm{~km}$ ) an overestimation of the aerosol backscatter coefficient is made. This effect is clearly visible in the mentioned plot. The correction of the depolarization effect is not implemented in the SCC because its application requires the mea- surement of the particle linear depolarization-ratio which is not yet a standard SCC product. However, the next SCC release will include the correction for depolarization effect as the implementation of quality-assured procedures to calculate the particle linear depolarization is planned.

Figures 7 and 8 are examples of comparisons of the Raman extinction retrievals. The curves in Fig. 7 are the aerosol extinction profiles at $355 \mathrm{~nm}$ obtained from the nitrogen vibrational-rotational Raman signal at $387 \mathrm{~nm}$ for the five different lidar systems, while Fig. 8 shows the aerosol extinction profiles at $532 \mathrm{~nm}$ calculated from the nitrogen vibrational-rotational Raman signal at $607 \mathrm{~nm}$ for the same systems. The agreement between the two independent analyses is good for both wavelengths. However, the extinction coefficient profiles at $532 \mathrm{~nm}$ are noisier than the ones at $355 \mathrm{~nm}$, and so, in some cases, it is not easy to clearly evaluate the agreement between manual and SCC analysis. Nevertheless, for all systems the atmospheric structures are present with very similar and consistent shape in the manually and the SCC retrieved profiles. The good agreement is also confirmed by the values of $\bar{d}$ and $\bar{d}_{\text {r }}$ reported in the bottom part of Table 1. For extinction coefficients, the maximum allowed relative and absolute deviations according to EARLINET requirements are $20 \%$ and $50 \mathrm{Mm}^{-1}$, respectively (Matthias et al., 2004). As a result, the SCC aerosol extinction retrieval meets the EARLINET requirements for all the considered systems at 355 and $532 \mathrm{~nm}$.

For all the profiles shown in Figs. 4-8, the molecular contribution to atmospheric extinction and transmissivity has been calculated using the atmospheric temperature and pressure profiles measured by a radiosounding correlative to the lidar measurement session. 
Table 2. Number of MUSA (Potenza) and Polly XT (Leipzig) measurement cases included in the calculation of the mean profiles shown in Figs. 9-13. The quantity $b 1064$ indicates the backscatter coefficient profile derived with the iterative method at $1064 \mathrm{~nm}$ while $b 532$ (b355) and $e 532$ (e355) represent backscatter and extinction coefficient profiles at $532 \mathrm{~nm}(355 \mathrm{~nm})$, respectively.

\begin{tabular}{lllll}
\hline & \multicolumn{2}{c}{ Night-time } & \multicolumn{2}{c}{ Daytime } \\
& MUSA & PollyXT & MUSA & Polly XT \\
\hline$b 1064$ & 23 & 15 & 12 & 9 \\
$b 532$ & 20 & 15 & 12 & 9 \\
$b 355$ & 24 & 15 & 10 & 9 \\
$e 532$ & 16 & 15 & - & - \\
$e 355$ & 14 & 15 & - & - \\
\hline
\end{tabular}

\subsection{Validation based on climatological data}

In the previous section, comparisons of the SCC analysis with the corresponding manual ones for a single measurement case were shown, considering several different lidar systems. This comparison allowed us to investigate the ability of the SCC to provide aerosol optical properties for different systems, but it did not assure that the algorithms implemented in the SCC are not affected by systematic errors or that they work well under different atmospheric conditions. To prove this ability, mean SCC profiles have been compared to the corresponding mean profiles obtained by an independent analysis procedure. In particular, several measurement cases have been inverted with both the SCC and the manual analysis software (the same manual software used so far to provide profiles to the EARLINET database). The results have been averaged and finally compared. Two representative EARLINET lidar systems have been taken into account for this comparison: MUSA (Madonna et al., 2011) and Polly XT (Althausen et al., 2013) operating at the Potenza and Leipzig stations, respectively.

For the Potenza station we have compared the mean profiles obtained by averaging the measurements made with the MUSA system in correlation with CALIPSO (Cloud-Aerosol Lidar and Infrared Pathfinder Satellite Observations, Winker et al., 2007) overpasses between March 2010 and November 2011. In Table 2, we summarized the number of single profiles that have been considered in calculating the mean profiles for both SCC and manual analysis. The quantity $b 1064$ indicates the backscatter coefficient profile at $1064 \mathrm{~nm}$ while b532 (b355) and e532 (e355) represent the backscatter and extinction coefficient profiles at $532 \mathrm{~nm}(355 \mathrm{~nm})$, respectively. The number of averaged profiles are not the same for all quantities as it was not possible to get optical products for all lidar channels for all cases. For night-time conditions, backscatter coefficients at 532 and $355 \mathrm{~nm}$ have been obtained using the Raman method. For daytime conditions, the backscatter coefficients at all wavelengths are calculated with the iterative method.
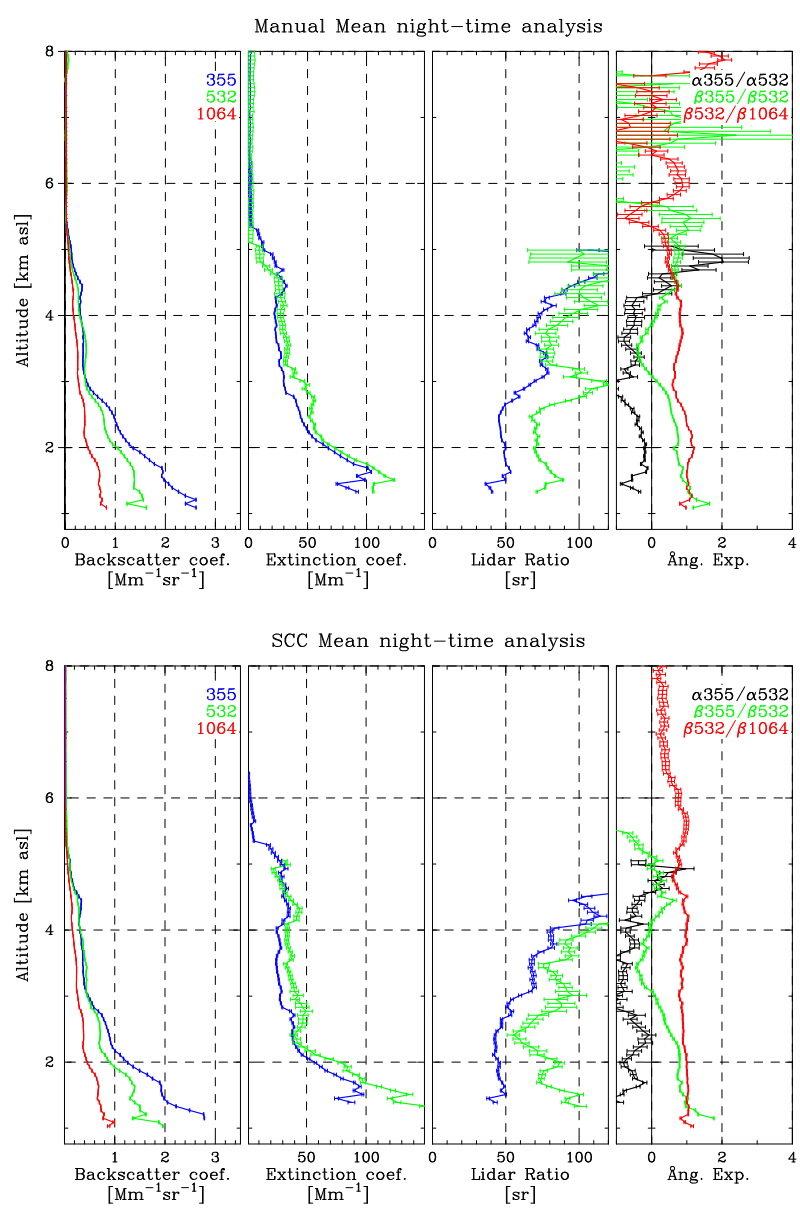

Figure 9. Mean night-time analysis comparison for the Potenza station (MUSA system). In the upper graph the mean profiles obtained using the manual analysis are shown, while in the bottom graph the results obtained by the SCC are presented. Several measurement cases (see Table 2) have been analysed, and the corresponding backscatter and extinction profiles have been averaged (left two panels of each graph). The other two panels of each graph show the lidar ratios and the Ångström exponents, respectively as calculated from the mean aerosol extinction and backscatter profiles.

Figure 9 summarizes the results of the comparison made for night-time conditions. For each analysis three mean backscatter coefficient profiles (first plot on the left) at $1064 \mathrm{~nm}$ (red curve), $532 \mathrm{~nm}$ (green curve), and $355 \mathrm{~nm}$ (blue curve) and two mean extinction coefficient profiles (second plot from the left) at $532 \mathrm{~nm}$ (green curve) and $355 \mathrm{~nm}$ (blue curve) are reported. In the same figure other important aerosol parameters are plotted which are directly derived from the extinction and backscatter coefficient profiles: the extinction-to-backscatter ratio (lidar ratio) and the Ångström exponents. As it is well known that these parameters depend only on the type of aerosol, it is quite interesting to test the SCC performance with respect to these parameters.

In general, the agreement between the two analyses is good for all profiles shown in Fig. 9. Table 3 and Fig. 11 pro- 
Table 3. Comparison of the mean values and standard errors of the mean for the profiles of the Potenza station shown in Figs. 9 and 10. Mean values and standard errors of the mean (reported in parentheses) were calculated by averaging the mean profiles within Range 1 (0-2 km) and Range $2(2-4 \mathrm{~km})$.

\begin{tabular}{|c|c|c|c|c|c|c|c|c|}
\hline \multirow[b]{3}{*}{$\lambda[\mathrm{nm}]$} & \multicolumn{6}{|c|}{ Night-time } & \multirow{2}{*}{\multicolumn{2}{|c|}{$\frac{\text { Daytime }}{\beta\left[\mathrm{Mm}^{-1} \mathrm{sr}^{-1}\right]}$}} \\
\hline & \multicolumn{2}{|c|}{$\beta\left[\mathrm{Mm}^{-1} \mathrm{sr}^{-1}\right]$} & \multicolumn{2}{|c|}{$\alpha\left[\mathrm{Mm}^{-1}\right]$} & \multicolumn{2}{|c|}{$\mathrm{LR}[\mathrm{sr}]$} & & \\
\hline & Manual & SCC & Manual & SCC & Manual & SCC & Manual & SCC \\
\hline & Range 1 & & & & & & & \\
\hline 355 & $2.01(0.10)$ & $1.97(0.12)$ & $86.42(3.52)$ & $79.53(4.32)$ & $47.23(1.65)$ & $45.48(1.04)$ & $1.58(0.07)$ & $1.60(0.09)$ \\
\hline 532 & $1.35(0.04)$ & $1.38(0.07)$ & $100.00(4.57)$ & $108.35(6.99)$ & $76.64(1.78)$ & $85.17(2.99)$ & $0.85(0.03)$ & $0.87(0.04)$ \\
\hline \multirow[t]{2}{*}{1064} & $0.65(0.02)$ & $0.69(0.03)$ & - & - & - & - & $0.53(0.01)$ & $0.57(0.02)$ \\
\hline & Range 2 & & & & & & & \\
\hline 355 & $0.62(0.06)$ & $0.60(0.05)$ & $34.74(2.04)$ & $32.28(1.31)$ & $61.71(2.13)$ & $59.76(2.46)$ & $0.50(0.04)$ & $0.48(0.04)$ \\
\hline 532 & $0.54(0.03)$ & $0.53(0.03)$ & $43.81(2.17)$ & $41.73(1.39)$ & $84.39(2.52)$ & $81.01(2.31)$ & $0.37(0.02)$ & $0.36(0.02)$ \\
\hline 1064 & $0.29(0.01)$ & $0.29(0.01)$ & - & - & 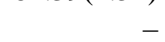 & 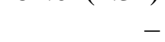 & $0.27(0.01)$ & $0.26(0.01)$ \\
\hline
\end{tabular}
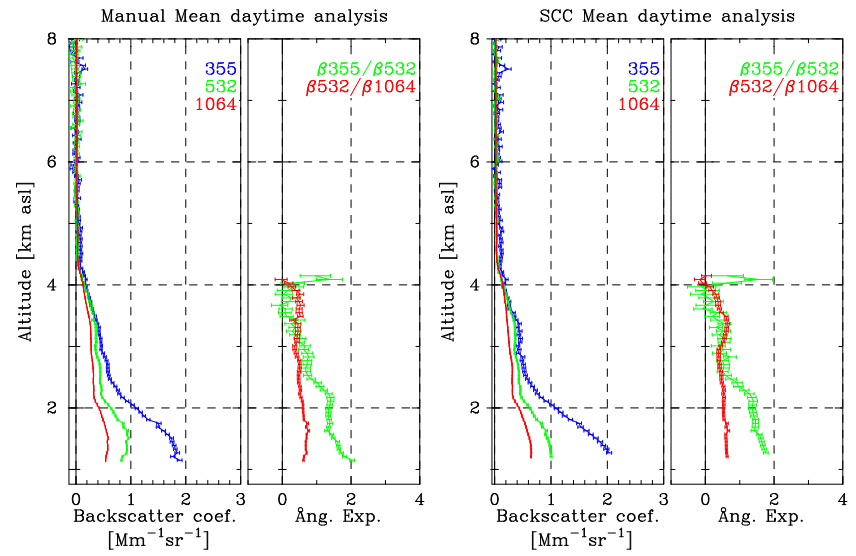

Figure 10. Mean daytime analysis comparison for the Potenza station (MUSA system). On the left the mean analysis obtained using the manual analysis is shown, while on the right the results obtained by the SCC are presented. Several measurement cases (see Table 2) have been analysed, and the corresponding backscatter profiles have been averaged (left two panels of each graph). The other panel of each graph shows the backscatter related Ångström exponents as calculated from the mean backscatter profiles.

vide a more quantitative comparison. In particular, two separate altitude ranges were selected in order to allow a direct comparison of statistical quantities. As most of the aerosol load is trapped below $4 \mathrm{~km}$ height, the first one (Range 1) extends up to $2 \mathrm{~km}$ and the second one (Range 2) from 2 up to $4 \mathrm{~km}$ height. For all vertical profiles plotted in Fig. 9, mean values and standard errors of the mean within Range 1 and Range 2 have been calculated and reported in Table 3. The agreement on the backscatter-related mean values and standard errors is quite good for both Range 1 and Range 2. The mean values calculated within Range 2 for the aerosol extinction mean profiles agree slightly better than the ones calculated within Range 1 . The general good agreement is also
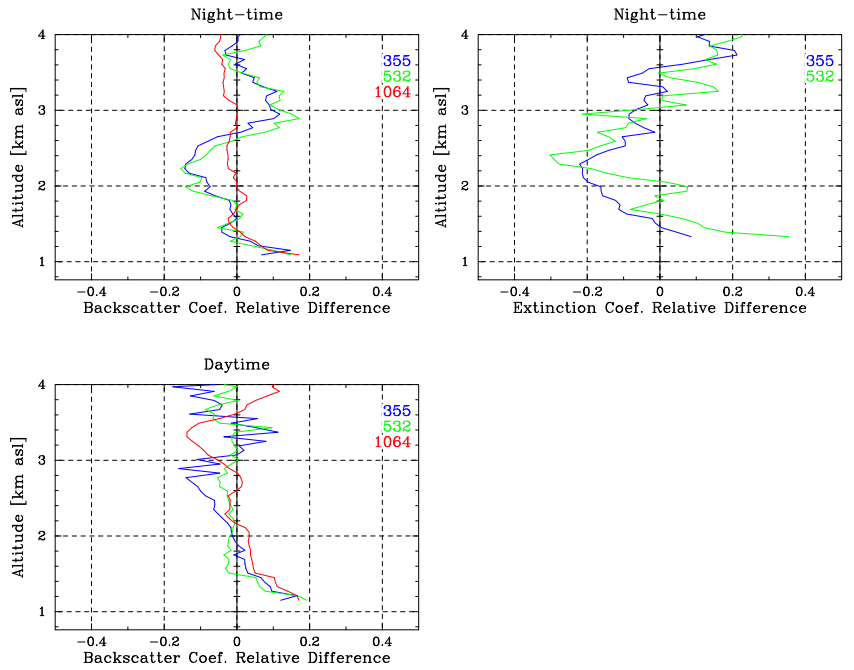

Figure 11. Relative differences between SCC and corresponding manually retrieved mean profiles for the Potenza station (MUSA system). On the left (upper part) the deviation between night-time mean aerosol backscatter profiles at 355, 532, and $1064 \mathrm{~nm}$ (see Fig. 9) are shown. On the right (upper part) the deviations between night-time mean aerosol extinction profiles at 355 and $532 \mathrm{~nm}$ (see Fig. 9) are reported. In the bottom part the deviation between daytime mean aerosol backscatter profiles at 355, 532, and $1064 \mathrm{~nm}$ (see Fig. 10) are shown.

confirmed by the two plots in the upper part of Fig. 11 showing the relative difference (below $4 \mathrm{~km}$ height) of the aerosol backscatter and extinction mean profiles displayed in Fig. 9.

In Fig. 10 the comparison for the MUSA system under daytime conditions is shown. As already mentioned, in this case the two Raman channels are not available and so it is only possible to compare backscatter-related quantities. As it can be seen from Table 3, also for daytime conditions we have a good agreement between the two analyses. The same 
conclusion is supported also by the mean deviations shown in the bottom part of Fig. 11 which, typically, vary between $\pm 10 \%$.

For the Leipzig station, we have compared all regular EARLINET climatology and CALIPSO measurements made by Polly ${ }^{X T}$ from September 2012 to September 2014 for which the complete data set of three backscatter coefficient and, at night-time, two extinction coefficient profiles were available. The numbers of Polly ${ }^{X T}$ single profiles that have been included in the calculation of mean profiles are reported in Table 2.

Figures 12 and 13 show the results of the comparison for the Polly ${ }^{\mathrm{XT}}$ system made under night-time and daytime conditions, respectively. All quantities displayed in these figures are the same already described in Figs. 9 and 10. The agreement between the two analyses is good in both cases. All manually calculated profiles plotted in Figs. 12 and 13 agree well with the corresponding ones calculated by the SCC. Moreover, the same quantitative comparison made for the MUSA system has been carried out also for the Polly ${ }^{\mathrm{XT}}$ lidar. The results are summarized in Table 4 and Fig. 14. In particular, Table 4 shows a very good agreement of both mean values and standard errors calculated within Range 1 and Range 2. The differences of the backscatter coefficient mean profiles at $355 \mathrm{~nm}$ are mainly due to the polarization sensibility of the Polly ${ }^{\mathrm{XT}}$ system at this wavelength. As already mentioned in the previous section, this effect is corrected in the manual analysis but not yet in the SCC. The deviations of the aerosol extinction mean profiles below $1.5 \mathrm{~km}$ are probably related to small differences in handling the correction for not complete overlap.

From the comparison discussed in this section we can conclude that the SCC performs well under different atmospheric conditions and for different systems. Of course, further comparisons and evaluations of SCC products are planned in the near future especially when more statistical data will be available.

\section{Example of near-real-time applicability}

In this section the main objectives of this $72 \mathrm{~h}$ operationally exercise are briefly recalled and some specific technical details about how the SCC has been used during that period are described. In July 2012, 11 EARLINET stations performed an intense period of coordinated measurements with a well defined measurement protocol. The measurements started on 9 July at 06:00 UT and continued without interruption for $72 \mathrm{~h}$ whenever the atmospheric conditions allowed lidar measurements. The details of this quite intensive observation period are provided in Sicard et al. (2015). The main aim of the $72 \mathrm{~h}$ operationally exercise was to provide a large set of aerosol parameters obtained in a standardized way for a large number of stations in near-real time. Especially the SCC was used to retrieve both pre-processed products in real time
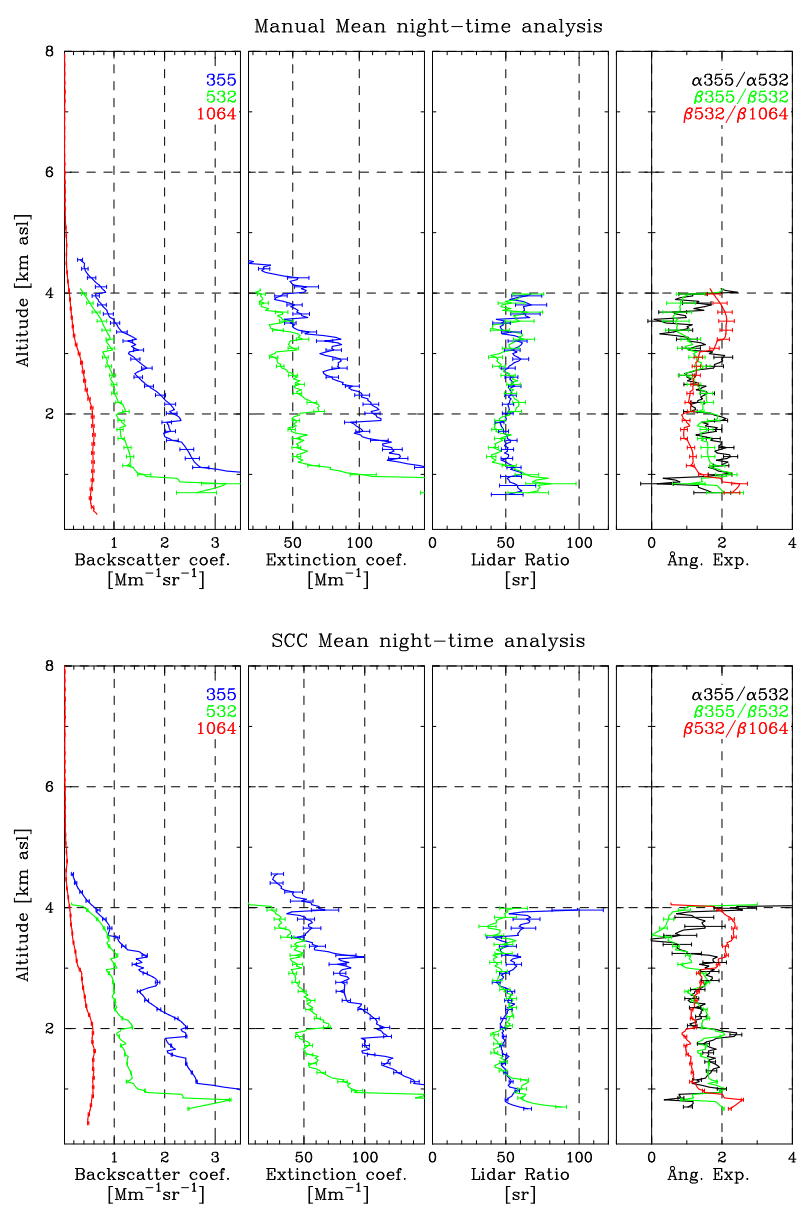

Figure 12. Mean night-time analysis comparison for the Leipzig station (Polly ${ }^{\mathrm{XT}}$ system). In the upper graph the mean profiles obtained using the manual analysis are shown, while in the bottom graph the results obtained by the SCC are presented. Several measurement cases (see Table 2) have been analysed, and the corresponding backscatter and extinction profiles have been averaged (left two panels of each graph). The other two panels of each graph show the lidar ratios and the Ångström exponents, respectively as calculated from the mean aerosol extinction and backscatter profiles.

(mainly range-corrected lidar signals) and optical products in near-real time for all stations participating in the exercise. The outputs of the SCC produced in that way can be used for a large variety of applications like the assimilation of lidar data in air-quality or dust transport models, model validation, or monitoring of special events like volcano eruptions. In particular, the SCC pre-processed data measured during the $72 \mathrm{~h}$ operationally exercise have been successfully assimilated in the air-quality model Polyphemus developed by the Centre d'Enseignement et de Recherche en Environnement Atmosphérique (CEREA) to improve the quality of $\mathrm{PM}_{10}$ and $\mathrm{PM}_{2.5}$ forecast on the ground (Wang et al., 2014).

All participating stations agreed to provide raw data in SCC format containing $1 \mathrm{~h}$ time series of raw lidar signals 
Table 4. Comparison of the mean values and standard errors of the mean for the profiles of the Leipzig station shown in Figs. 12 and 13. Mean values and standard errors of the mean (reported in parentheses) were calculated by averaging the mean profiles within Range 1 (0-2 km) and Range $2(2-4 \mathrm{~km})$.

\begin{tabular}{|c|c|c|c|c|c|c|c|c|}
\hline \multirow[b]{3}{*}{$\lambda[\mathrm{nm}]$} & \multicolumn{6}{|c|}{ Night-time } & \multirow{2}{*}{\multicolumn{2}{|c|}{$\frac{\text { Daytime }}{\beta\left[\mathrm{Mm}^{-1} \mathrm{sr}^{-1}\right]}$}} \\
\hline & \multicolumn{2}{|c|}{$\beta\left[\mathrm{Mm}^{-1} \mathrm{sr}^{-1}\right]$} & \multicolumn{2}{|c|}{$\alpha\left[\mathrm{Mm}^{-1}\right]$} & \multicolumn{2}{|c|}{$\mathrm{LR}[\mathrm{sr}]$} & & \\
\hline & Manual & SCC & Manual & SCC & Manual & SCC & Manual & $\mathrm{SCC}$ \\
\hline & Range 1 & & & & & & & \\
\hline 355 & $3.16(0.22)$ & $3.03(0.19)$ & $168.93(13.4)$ & $157.51(11.3)$ & $52.21(0.59)$ & $51.09(0.57)$ & $2.30(0.23)$ & $2.45(0.26)$ \\
\hline 532 & $1.56(0.10)$ & $1.55(0.09)$ & $88.81(9.13)$ & $85.33(7.96)$ & $52.85(1.85)$ & $52.54(1.62)$ & $1.00(0.08)$ & $0.98(0.07)$ \\
\hline \multirow[t]{2}{*}{1064} & $0.58(0.01)$ & $0.56(0.01)$ & - & - & - & - & $0.48(0.03)$ & $0.47(0.03)$ \\
\hline & Range 2 & & & & & & & \\
\hline 355 & $1.39(0.05)$ & $1.47(0.06)$ & $75.81(2.70)$ & $76.80(2.52)$ & $55.37(0.67)$ & $54.15(1.22)$ & $0.20(0.01)$ & $0.24(0.02)$ \\
\hline 532 & $0.86(0.02)$ & $0.94(0.02)$ & $45.84(1.50)$ & $45.33(1.39)$ & $53.09(0.75)$ & $48.17(0.58)$ & $0.08(0.01)$ & $0.11(0.01)$ \\
\hline 1064 & $0.32(0.02)$ & $0.31(0.02)$ & - & - & 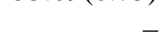 & 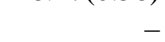 & $0.06(0.01)$ & $0.06(0.01)$ \\
\hline
\end{tabular}
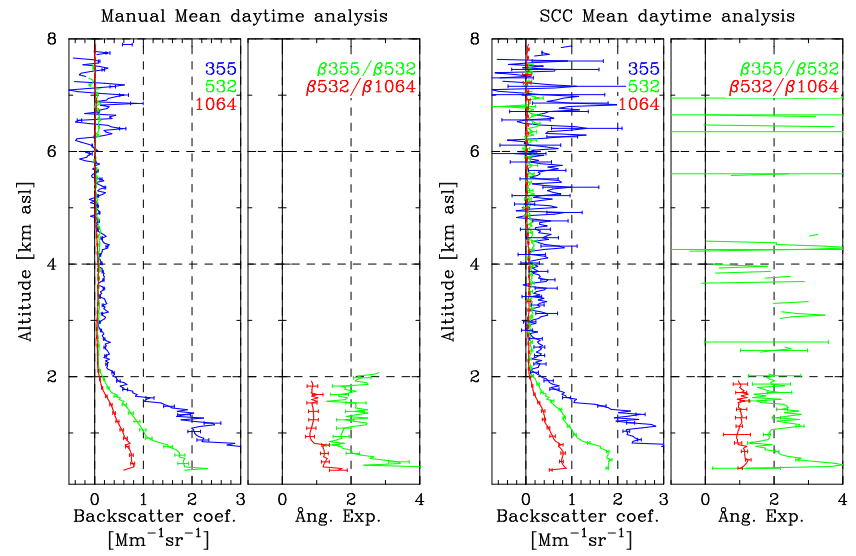

Figure 13. Mean daytime analysis comparison for the Leipzig station (Polly ${ }^{\mathrm{XT}}$ system). On the left the mean analysis obtained using the manual analysis is shown, while on the right the results obtained by the SCC are presented. Several measurement cases (see Table 2) have been analysed, and the corresponding backscatter profiles have been averaged (left two panels of each graph). The other panel of each graph shows the backscatter related Ångström exponents as calculated from the mean backscatter profiles.

synchronized to the start of each hour. Starting from these raw data files the SCC was configured to provide $30 \mathrm{~min}$ time-averaged range-corrected signals (pre-processed files) for all involved lidar systems. During the exercise the SCC was an important tool toward the standardization of lidar products as the participating lidars operate at different raw time resolutions (from 1 to $5 \mathrm{~min}$ ) and they also differ in many other characteristics requiring different instrumental corrections.

To make the SCC outputs available as soon as possible, an infrastructure was set up to automatically submit the data to the SCC. To start the retrieval of the SCC on a particular measurement the user needs to register the measurement
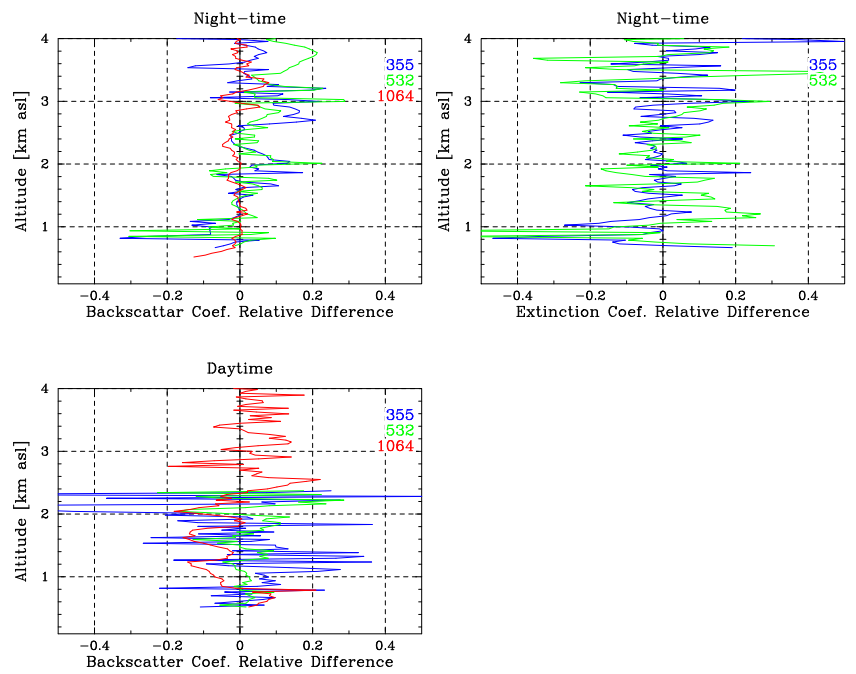

Figure 14. Relative differences between SCC and corresponding manually retrieved mean profiles for the Leipzig station (Polly ${ }^{\mathrm{XT}}$ system). On the left (upper part) the deviation between nighttime mean aerosol backscatter profiles at 355, 532, and $1064 \mathrm{~nm}$ (see Fig. 12) are shown. On the right (upper panel) the deviations between night-time mean aerosol extinction profiles at 355 and $532 \mathrm{~nm}$ (see Fig. 12) are reported. In the bottom part the deviation between daytime mean aerosol backscatter profiles at 355, 532, and $1064 \mathrm{~nm}$ (see Fig. 13) are shown.

into the SCC database using the web interface. This operation needs time and also the presence of an operator. To improve that, a fully automatic uploading system has been implemented and used during the $72 \mathrm{~h}$ measurement exercise. Once the system has detected the presence of a new measurement, a check on the format of the uploaded data file is automatically performed and in case of success the measurement is automatically registered to the SCC database and consequently the SCC is started on it. The results of the SCC 
analysis are sent back to the originator for their evaluation as soon as they are available. With such a system it was possible to automatically retrieve the needed aerosol optical products and make them available within 30 min from the end of measurement.

\section{Conclusions}

The SCC, an automatic tool for the analysis of EARLINET lidar data, has been developed and made available to all EARLINET stations. The SCC has been installed on a centralized server where the user can submit data using a predefined NetCDF structure. The SCC is highly configurable and can be easily adapted to new lidar systems. In particular, a user-friendly web interface allows the user to change all instrumental and configuration parameters to be used in the analysis. The products of the SCC are all quality certified in terms of the EARLINET quality assurance program. The SCC can provide different levels of output: preprocessed signals (range-corrected lidar signals corrected for all instrumental effects) and aerosol optical products (aerosol backscatter and extinction coefficient profiles). The pre-processed and the aerosol optical products are calculated by two different SCC modules: the ELPP module which accepts as input the raw lidar data and the ELDA module which takes as inputs the outputs of the ELPP module. The actions of the two modules are automatically synchronized and coordinated by another module called SCC daemon. All parameters required by the ELPP and ELDA modules are stored in an efficient way in the SCC database.

The SCC has been validated by Mattis et al. (2016) using synthetic lidar signals used during the EARLINET algorithm inter-comparison exercise and, in this paper, using real lidar data. In particular, the validation with real lidar data was accomplished by comparing the SCC optical products with the corresponding products retrieved with independent manual quality-certified procedures. The validation was carried out in two different steps. First, considering a case study selected from the EARLI09 inter-comparison campaign, it was proved that the SCC is able to provide optical products in good agreement with the corresponding manual analysis for all EARLI09 lidar systems considered. Second, it was checked that the SCC can provide reliable results in different atmospheric conditions. This was achieved by performing a statistical analysis of the long-term data set of two EARLINET stations. The comparisons indicated a good performance of the SCC as well.
An example of the applicability of the SCC was provided by describing the use of the SCC during the $72 \mathrm{~h}$ EARLINET measurement exercise. In this case, the SCC delivered highquality aerosol properties at different levels (pre-processed signals and aerosol optical products) in near-real time. Such products can be assimilated in models or can be used for model validation purposes or to monitor special events at network level.

The development of the SCC modules is continuing. New features like particle depolarization-ratio calculation, automatic determination of aerosol layer properties from both geometrical and optical point of view, and cloud masking are under investigation and will be included in the SCC in the framework of the ACTRIS and ACTRIS-2 projects (http://www.actris.eu). Due to its flexibility the SCC could be easily extended to GALION to evaluate lidar data of networks different from EARLINET. 


\section{Appendix A: SCC usecases description}

In this Appendix, all usecases currently implemented in the SCC are described. A specific nomenclature has been used to uniquely identify the different types of lidar signals detected by all EARLINET lidars. In particular, the name assigned to each lidar signal is composed of four different substrings grouped by the character underscore. The first substring describes the scattering mode characterizing the detected signal, the second identifies the polarization state, the third describes the detection mode used to measure the signal, and finally the fourth one identifies the range for which the signal is optimized. For example, a channel called "elT_cross_pc_fr" represents the photon-counting perpendicular polarization component (with respect to the direction of linear-polarized incident laser light) of the elastically backscattered lidar signal optimized (in terms of the signalto-noise ratio) to detect the atmospheric signal from the farrange. Table A1 summarizes all possible substrings used to identify the signals.
All implemented usecases, separated by product type, are reported in the Tables A2, A3 and A4 using the same structure. The first column gives the number identifying the usecase. This number uniquely identifies the usecase once a product type has to be selected. The second column reports all lidar channels involved in the product calculation. This information allows the identification of the relevant usecases fitting with one specific experimental setup. The other columns specify the steps to be performed in the calculation of the product. The third column shows which channels are combined at pre-processing level typically to enhance the detected dynamic range by gluing signals optimized for the far range with the corresponding ones optimized for the near range (D'Amico et al., 2015). The fourth column specifies which pre-processed signals are used to calculate the corresponding optical product. If in this column only one subcolumn is present (e.g., the usecase 7 in Table A2), it means the final product is directly calculated using the selected preprocessed signal. If there are two subcolumns (e.g., the usecase 4 in Table A2), two products are calculated in the processing phase (typically one for the far range and one for the near range) and then these products are combined to get the final product. The presence of product combination in the usecase is specified by the last column of the tables. It is worth mentioning that each usecase always corresponds to a single optical product.

Table A1. Nomenclature used to identify univocally the different types of lidar signals detected by all EARLINET lidar systems.

\begin{tabular}{|c|c|}
\hline Name & Description \\
\hline \multicolumn{2}{|c|}{ Scattering mode } \\
\hline $\begin{array}{l}\text { el } \\
\text { vrN2 } \\
\text { pRRlow } \\
\text { pRRhigh }\end{array}$ & $\begin{array}{l}\text { elastically backscattered signal } \\
\text { vibrational-rotational Raman backscattered signal by nitrogen molecules } \\
\text { pure rotational Raman backscattered signal at low quantum number } \\
\text { pure rotational Raman backscattered signal at high quantum number }\end{array}$ \\
\hline \multicolumn{2}{|c|}{ Polarization state } \\
\hline $\begin{array}{l}\text { tot } \\
\text { cross } \\
\text { paral }\end{array}$ & $\begin{array}{l}\text { total signal } \\
\text { perpendicular polarization component } \\
\text { parallel polarization component }\end{array}$ \\
\hline \multicolumn{2}{|c|}{ Detection mode } \\
\hline $\begin{array}{l}\text { an } \\
\text { pc } \\
\text { any }\end{array}$ & $\begin{array}{l}\text { analog } \\
\text { photon-counting } \\
\text { can be analog or photon-counting }\end{array}$ \\
\hline \multicolumn{2}{|c|}{ Range mode* } \\
\hline $\begin{array}{l}\text { fr } \\
\mathrm{nr} \\
\mathrm{unr}\end{array}$ & $\begin{array}{l}\text { signal optimized to detect the far range } \\
\text { signal optimized to detect the near range } \\
\text { signal optimized to detect the ultra-near range }\end{array}$ \\
\hline
\end{tabular}


Table A2. SCC usecases implemented for the calculation of the atmospheric particle backscatter coefficient profile using the Raman technique. The first column provides the number identifying the usecase, the second column reports all lidar channels involved in the product calculation, the third column shows which channels are combined at pre-processing level, the fourth column specifies which pre-processed signals are used to calculate the final optical product. Finally, the last column shows, if intermediate products have been combined to get the final optical product.

\begin{tabular}{|c|c|c|c|c|}
\hline Usecase & Channels & $\begin{array}{c}\text { Signal } \\
\text { combination }\end{array}$ & $\begin{array}{l}\text { Product } \\
\text { calculation }\end{array}$ & $\begin{array}{c}\text { Product } \\
\text { combination }\end{array}$ \\
\hline \multirow{2}{*}{0} & el_tot_any & & $x$ & \\
\hline & vrRN2_tot_any & & $x$ & \\
\hline \multirow{3}{*}{1} & el_tot_any_nr & $x$ & \multirow{2}{*}{$x$} & \\
\hline & el_tot_any_fr & $x$ & & \\
\hline & vrRN2_tot_any & & $x$ & \\
\hline \multirow{3}{*}{2} & el_tot_any_nr & & $x$ & \\
\hline & el_tot_any_fr & & $x$ & $x$ \\
\hline & vrRN2_tot_any & & $x$ & \\
\hline \multirow{3}{*}{3} & el_tot_any & & $x$ & \\
\hline & vrRN2_tot_any_nr & $x$ & \multirow{2}{*}{$x$} & \\
\hline & vrRN2_tot_any_fr & $x$ & & \\
\hline \multirow{3}{*}{4} & el_tot_any & & $\times$ & \\
\hline & vrRN2_tot_any_nr & & $x$ & $x$ \\
\hline & vrRN2_tot_any_fr & & $x$ & \\
\hline \multirow{4}{*}{5} & el_tot_any_nr & $x$ & \multirow{2}{*}{$x$} & \\
\hline & el_tot_any_fr & $x$ & & \\
\hline & vrRN2_tot_any_nr & $\times$ & \multirow{2}{*}{$x$} & \\
\hline & vrRN2_tot_any_fr & $x$ & & \\
\hline \multirow{4}{*}{6} & el_tot_any_nr & & $x$ & \\
\hline & el_tot_any_fr & & $x$ & \\
\hline & vrRN2_tot_any_nr & & $\times$ & $x$ \\
\hline & vrRN2_tot_any_fr & & $x$ & \\
\hline \multirow{3}{*}{7} & el_cross_any & & $x$ & \\
\hline & el_paral_any & & $x$ & \\
\hline & vrRN2_tot_any & & $x$ & \\
\hline \multirow{3}{*}{8} & el_tot_any & & $x$ & \\
\hline & pRRlow_tot_any & $x$ & \multirow{2}{*}{$x$} & \\
\hline & pRRhigh_tot_any & $x$ & & \\
\hline \multirow{5}{*}{9} & el_cross_any_nr & $x$ & \multirow{2}{*}{$x$} & \\
\hline & el_cross_any_fr & $x$ & & \\
\hline & el_paral_any_nr & $x$ & \multirow{2}{*}{$\times$} & \\
\hline & el_paral_any_fr & $x$ & & \\
\hline & vrRN2_tot_any & & $x$ & \\
\hline \multirow{4}{*}{10} & el_cross_any & & $x$ & \\
\hline & el_paral_any & & $x$ & \\
\hline & vrRN2_tot_any_nr & $x$ & & \\
\hline & vrRN2_tot_any_fr & $x$ & $x$ & \\
\hline
\end{tabular}


Table A2. Continued.

\begin{tabular}{|c|c|c|c|c|}
\hline Usecase & Channels & $\begin{array}{c}\text { Signal } \\
\text { combination }\end{array}$ & $\begin{array}{l}\text { Product } \\
\text { calculation }\end{array}$ & $\begin{array}{c}\text { Product } \\
\text { combination }\end{array}$ \\
\hline \multirow{6}{*}{11} & el_cross_any_nr & $x$ & \multirow{2}{*}{$\times$} & \\
\hline & el_cross_any_fr & $x$ & & \\
\hline & el_paral_any_nr & $x$ & \multirow{2}{*}{$x$} & \\
\hline & el_paral_any_fr & $x$ & & \\
\hline & vrRN2_tot_any_nr & $x$ & \multirow{2}{*}{$x$} & \\
\hline & vrRN2_tot_any_fr & $x$ & & \\
\hline \multirow{6}{*}{12} & el_cross_any_nr & & $x$ & \\
\hline & el_cross_any_fr & & $x$ & \\
\hline & el_paral_any_nr & & $x$ & \\
\hline & el_paral_any_fr & & $x$ & $x$ \\
\hline & vrRN2_tot_any_nr & & $x$ & \\
\hline & vrRN2_tot_any_fr & & $x$ & \\
\hline \multirow{8}{*}{13} & el_tot_an_nr & $\times$ & \multirow{4}{*}{$\times$} & \multirow{8}{*}{$x$} \\
\hline & el_tot_pc_nr & $x$ & & \\
\hline & vrRN2_tot_an_nr & $x$ & & \\
\hline & vrRN2_tot_an_nr & $x$ & & \\
\hline & el_tot_an_fr & $x$ & \multirow{2}{*}{$x$} & \\
\hline & el_tot_pc_fr & $x$ & & \\
\hline & vrRN2_tot_an_fr & $\times$ & Y & \\
\hline & vrRN2_tot_pc_fr & $x$ & $x$ & \\
\hline \multirow{7}{*}{14} & el_tot_any_unr & $x$ & \multirow{2}{*}{$x$} & \multirow{7}{*}{$x$} \\
\hline & el_tot_any_nr & $x$ & & \\
\hline & pRRlow_tot_any_nr & $x$ & \multirow{2}{*}{$x$} & \\
\hline & pRRhigh_tot_any_nr & $x$ & & \\
\hline & el_tot_any_fr & & $x$ & \\
\hline & pRRlow_tot_any_fr & $x$ & $x$ & \\
\hline & pRRhigh_tot_any_fr & $x$ & $x$ & \\
\hline \multirow{5}{*}{15} & el_tot_any_unr & $x$ & \multirow{2}{*}{$x$} & \multirow{5}{*}{$x$} \\
\hline & el_tot_any_nr & $x$ & & \\
\hline & vrRN2_tot_any_nr & & $x$ & \\
\hline & el_tot_any_fr & & $x$ & \\
\hline & vrRN2_tot_any_fr & & $x$ & \\
\hline \multirow{6}{*}{16} & el_tot_any_nr & & \multirow[t]{3}{*}{$x$} & \multirow{6}{*}{$x$} \\
\hline & pRRlow_tot_any_nr & $x$ & & \\
\hline & pRRhigh_tot_any_nr & $x$ & & \\
\hline & el_tot_any_fr & & $x$ & \\
\hline & pRRlow_tot_any_fr & $x$ & \multirow{2}{*}{$\times$} & \\
\hline & pRRhigh_tot_any_fr & $x$ & & \\
\hline
\end{tabular}


Table A2. Continued.

\begin{tabular}{clccc}
\hline Usecase & Channels & $\begin{array}{c}\text { Signal } \\
\text { combination }\end{array}$ & $\begin{array}{c}\text { Product } \\
\text { calculation }\end{array}$ & $\begin{array}{c}\text { Product } \\
\text { combination }\end{array}$ \\
\hline \multirow{3}{*}{17} & $\begin{array}{l}\text { el_paral_any_nr } \\
\text { el_paral_any_fr }\end{array}$ & $\times$ & $\times$ & \\
\cline { 2 - 3 } & el_cross_any & & $\times$ & \\
& vrRN2_tot_any & & $\times$ \\
\hline \multirow{3}{*}{18} & el_cross_any_nr & $\times$ & & \\
& el_cross_any_fr & $\times$ & & \\
\cline { 2 - 3 } & el_paral_any & & $\times$ & \\
& vrRN2_tot_any & & $\times$ \\
\hline
\end{tabular}

Table A3. SCC usecases implemented for the calculation of the atmospheric particle extinction coefficient profile using the Raman technique. The structure of the table is the same one as in Table A2.

\begin{tabular}{|c|c|c|c|c|}
\hline Usecase & Channels & $\begin{array}{c}\text { Signal } \\
\text { combination }\end{array}$ & $\begin{array}{c}\text { Product } \\
\text { calculation }\end{array}$ & $\begin{array}{c}\text { Product } \\
\text { combination }\end{array}$ \\
\hline 0 & vrRN2_tot_any & \multicolumn{3}{|c|}{$x$} \\
\hline \multirow{2}{*}{1} & vrRN2_tot_any_nr & $x$ & \multirow{2}{*}{$x$} & \\
\hline & vrRN2_tot_any_fr & $x$ & & \\
\hline \multirow{2}{*}{2} & vrRN2_tot_any_nr & & \multirow[t]{2}{*}{$x$} & $x$ \\
\hline & vrRN2_tot_any_fr & & & $x$ \\
\hline \multirow{2}{*}{3} & pRRlow_tot_any & $x$ & \multirow{2}{*}{$x$} & \\
\hline & pRRhigh_tot_any & $x$ & & \\
\hline \multirow{4}{*}{4} & vrRN2_tot_an_nr & $x$ & \multirow{2}{*}{$x$} & \multirow{4}{*}{$x$} \\
\hline & vrRN2_tot_pc_nr & $x$ & & \\
\hline & vrRN2_tot_an_fr & $x$ & \multirow{2}{*}{$x$} & \\
\hline & vrRN2_tot_pc_fr & $x$ & & \\
\hline \multirow{4}{*}{5} & pRRlow_tot_any_nr & $x$ & \multirow{2}{*}{$x$} & \multirow{4}{*}{$x$} \\
\hline & pRRhigh_tot_any_nr & $x$ & & \\
\hline & pRRlow_tot_any_fr & $x$ & \multirow{2}{*}{$x$} & \\
\hline & pRRhigh_tot_any_fr & $x$ & & \\
\hline
\end{tabular}


Table A4. SCC usecases implemented for the calculation of the atmospheric particle backscatter coefficient profile using the elastic-only technique. The structure of the table is the same one as in Table A2.

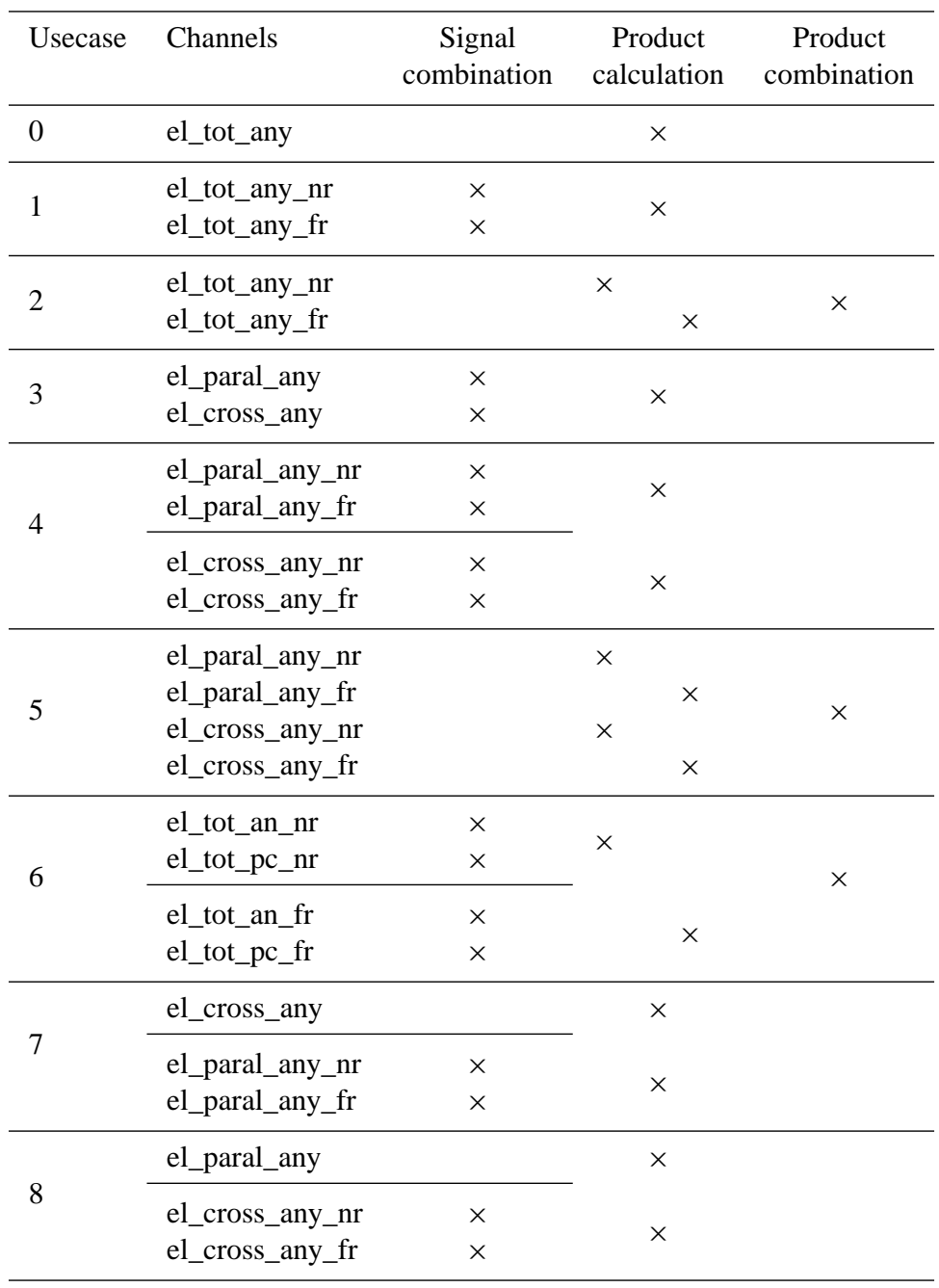


Acknowledgements. The financial support for EARLINET in the ACTRIS Research Infrastructure Project by the European Union's Horizon 2020 research and innovation programme under grant agreement no. 654169 and previously under the grants no. 262254 in the 7th Framework Programme (FP7/2007-2013) and no. 025991 in the 6th Framework Programme (FP6/2002-2006) is gratefully acknowledged.

Ioannis Binietoglou would like to acknowledge funding received from the European Union's Seventh Framework Programme for research, technological development and demonstration under grant agreement no 289923 - ITaRS.

Edited by: A. Ansmann

\section{References}

Ackermann, J.: The extinction-to-backscattering ratio of tropospheric aerosol: a numerical study, J. Atmos. Ocean. Technol., 15, 1043-1050, 1998.

Althausen, D., Engelmann, R., Baars, H., Heese, B., Kanitz, T., Komppula, M., Giannakaki, E., Pfüller, A., Silva, A. M., Preißler, I., Wagner, F., Rascado, J. L., Pereira, S., Lim, J., Ahn, J. Y., Tesche, M., and Stachlewska, I. S.: PollyNET: a network of multiwavelength polarization Raman lidars, in: Proc. of SPIE, vol. 8894, Lidar Technologies, Techniques, and Measurements for Atmospheric Remote Sensing IX, 88940I-1-88940I-10, International Society for Optical Engineering, P.O. Box 10, Bellingham, WA 98227-0010 USA, 2013.

Amodeo, A., D’Amico, G., Mattis, I., Freudenthaler, V., and Pappalardo, G.: Error calculation for EARLINET products in the context of quality assurance and single calculus chain, Atmos. Meas. Tech. Discuss., in preparation, 2016.

Ansmann, A., Riebesell, M., and Weitcamp, C.: Measurement of atmospheric aerosol extinction profiles with a Raman lidar, Opt. Lett., 15, 746-748, 1990.

Ansmann, A., Riebesell, M., Wandinger, U., Weitcamp, C., Voss, E., Lahmann, W., and Michaelis, W.: Combined Raman elasticbackscatter lidar for vertical profiling of moisture, aerosol extinction, backscatter and lidar ratio, Appl. Phys. B, 55, 18-28, 1992.

Böckmann, C.: Hybrid regularization method for the ill-posed inversion of multiwavelength lidar data in the retrieval of aeorosol size distributions, Appl. Optics, 40, 1329-1342, 2001.

Böckmann, C., Wandinger, U., Ansmann, A., Bösenberg, J., Amiridis, V., Boselli, A., Delaval, A., De Tomasi, F., Frioud, M., Grigorov, I. V., Hågård, A., Horvat, M., Iarlori, M., Komguem, L., Kreipl, S., Larchevêque, G., Matthias, V., Papayannis, A., Pappalardo, G., Rocadenbosch, F., Rodrigues, J. A., Schneider, J., Shcherbakov, V., and Wiegner, M.: Aerosol lidar intercomparison in the framework of the EARLINET project. 2.Aerosol backscatter algorithms, Appl. Opt., 43, 977-989, 2004.

Bösenberg, J., Hoff, R., Ansmann, A., Müller, D., Antuña, J. C., Whiteman, D., Sugimoto, N., Apituley, A., Hardesty, M., Welton, J., Eloranta, E., Arshinov, Y., Kinne, S., and Freudenthaler, V.: GAW Report No. 178: Plan for the implementation of the GAW Aerosol Lidar Observation Network GALION, Tech. rep., Geneva, World Meteorological Organization, available at: ftp://ftp.wmo.int/Documents/PublicWeb/arep/ gaw/gaw178-galion-27-Oct.pdf, 2008.
Chaikovsky, A., Ivanov, A., Balin, Y., Elnikov, A., Tulinov, G., Plusnin, I., Bukin, O., and Chen, B.: Lidar network CISLiNet for monitoring aerosol and ozone in CIS regions, in: Proc. of SPIE, vol. 6160, Twelfth Joint International Symposium on Atmospheric and Ocean Optics/Atmospheric Physics, 616035-1-616035-9, International Society for Optical Engineering, P.O. Box 10, Bellingham, WA 98227-0010 USA, 2006.

D’Amico, G., Amodeo, A., Mattis, I., Freudenthaler, V., and Pappalardo, G.: EARLINET Single Calculus Chain - technical - Part 1: Pre-processing of raw lidar data, Atmos. Meas. Tech. Discuss., 8, 10387-10428, doi:10.5194/amtd-8-10387-2015, 2015.

Di Girolamo, P., Gagliardi, R., Pappalardo, G., Spinelli, N., Velotta, R., and Berardi, V.: Two wavelength lidar analysis of stratospheric aerosol size distribution, J. Aerosol Sci., 26, 989-1001, 1995.

Diner, D. J., Ackerman, T., Anderson, T. L., Bösemberg, J., Braverman, A. J., Charlson, R. J., Collins, W. D., Davies, R., Holben, B. N., Hostetler, C. A., Kahn, R. A., Martonchik, J. V., Menzies, R. T., Miller, M. A., Ogren, J. A., Penner, J. E., Rasch, P. J., Schwartz, S. E., Seinfeld, J. H., Stephens, G. L., Torres, O., Travis, D. D., Wielicki, B. A., and Yu, B.: PARAGON: An Integrated Approach for Characterizing Aerosol Climate Impacts and Environmental Interactions, B. Am. Meteor. Soc., 85, 14911501, 2004.

Engelmann, R., Guerrero-Rascado, J. L., Alados-Arboledas, L., Wandinger, U., Freudenthaler, V., Baars, H., Mattis, I., Groß, S., Pappalardo, G., Amodeo, A., D’Amico, G., Giunta, A., Chaikovsky, A., Osipenko, F., Slesar, A., Nicolae, D., Belegante, L., Serikov, I., Linné, H., Jansen, F., Apituley, A., Wilson, K., Trickl, T., and Rocadenbosch, F.: Calibrated backscatter measurement at $1064 \mathrm{~nm}$ with lidar: Techniques used in EARLINET and ACTRIS, Atmos. Meas. Tech. Discuss., in preparation, 2016.

Fernald, F. G.: Analysis of atmospheric lidar observations: some comments, Appl. Optics, 23, 652-653, 1984.

Freudenthaler, V., Gross, S., Engelmann, R., Mattis, I., Wandinger, U., Pappalardo, G., Amodeo, A., Giunta, A., D’Amico, G., Chaikovsky, A., Osipenko, F., Slesar, A., Nicolae, D., Belegante, L., Talianu, C., Serikov, I., Linne, H., Jansen, F., Wilson, K., De Graaf, M., Apituley, A., Trickl, T., Giehl, H., and Adam, M.: EARLI09 - Direct intercomparison of 11 EARLINET lidar systems, in: Proceedings of 25th International Laser Radar Conference (ILRC), pp. 891-894, St. Petersburg, Russia, 5-9 July 2010, 2010.

Freudenthaler, V., Linné, H., Chaikovsky, A., Groß, S., and Rabus, D.: Internal quality assurance tools, Atmos. Meas. Tech. Discuss., in preparation, 2016.

Holben, B., Eck, T., Slutsker, I., Tanré, D., Buis, J., Setzer, A., Vermote, E., Reagan, J., Kaufman, Y., Nakajima, T., Lavenu, F., Jankowiak, I., and Smirnov, A.: AERONET-A Federated Instrument Network and Data Archive for Aerosol Characterization, Remote Sens. Environ., 66, 1-16, 1998.

Intergovernmental Panel on Climate Change: Fourth Assessment Report: Climate Change 2007: The AR4 Synthesis Report, Geneva: IPCC, available at: https://www.ipcc.ch/publications_ and_data/ar4/syr/en/main.html (last access: 9 November 2015), 2007.

Intergovernmental Panel on Climate Change: Climate Change 2013: The Physical Science Basis, Contribution of Working Group I to the Fifth Assessment Report of the Intergovernmen- 
tal Panel on Climate Change, Cambridge University Press, Cambridge, United Kingdom and New York, NY, USA, available at: http://www.climatechange2013.org (last access: 9 November 2015), 2013.

Johnson, F. A., Jones, R., McLean, T. P., and Pike, E. R.: Dead-Time Corrections to Photon Counting Distributions, Phys. Rev. Lett., 16, 589-592, 1966.

Klett, J. D.: Stable analytical inversion solution for processing lidar returns, Appl. Opt., 20, 211-220, 1981.

Klett, J. D.: Lidar inversion with variable backscatter/extinction ratios, Appl. Opt., 24, 1638-1643, 1985.

Madonna, F., Amodeo, A., Boselli, A., Cornacchia, C., Cuomo, V., D’Amico, G., Giunta, A., Mona, L., and Pappalardo, G.: CIAO: the CNR-IMAA advanced observatory for atmospheric research, Atmos. Meas. Tech., 4, 1191-1208, doi:10.5194/amt4-1191-2011, 2011.

Matthias, V., Freudenthaler, V., Amodeo, A., Balin, I., Balis, D., Bösenberg, J., Chaikovsky, A., Chourdakis, G., Comeron, A., Delaval, A., De Tomasi, F., Eixmann, R., Hågård, A., Komguem, L., Kreipl, S., Matthey, R., Rizi, V., Rodrigues, J. A., Wandinger, U., and Wang, X.: Aerosol lidar intercomparison in the framework of the EARLINET project. 1.Instruments: erratum, Appl. Opt., 43, 2578-2579, 2004.

Mattis, I., Ansmann, A., Wandinger, U., and Müller, D.: Unexpectedly high aerosol load in the free troposphere over central Europe in spring/summer 2003, Geophys. Res. Lett., 30, 2178, doi:10.1029/2003GL018442, 2003.

Mattis, I., Ansmann, A., Müller, D., Wandinger, U., and Althausen, D.: Multiyear aerosol observations with dual-wavelength Raman lidar in the framework of EARLINET, J. Geophys. Res., 109, D13203, doi:10.1029/2004JD004600, 2004.

Mattis, I., Tesche, M., Grein, M., Freudenthaler, V., and Müller, D.: Systematic error of lidar profiles caused by a polarizationdependent receiver transmission: quantification and error correction scheme, Appl. Opt., 48, 2742-2751, 2009.

Mattis, I., D’Amico, G., Madonna, F., Amodeo, A., and Baars, H.: EARLINET Single Calculus Chain - technical - Part 2: Calculation of optical products, Atmos. Meas. Tech. Discuss., in preparation, 2016.

Müller, D., Wandinger, U., and Ansmann, A.: Microphysical particle parameters from extinction and backscatter lidar data by inversion with regularization: theory, Appl. Opt., 38, 2346-2357, 1999a.

Müller, D., Wandinger, U., and Ansmann, A.: Microphysical particle parameters from extinction and backscatter lidar data by inversion with regularization: simulation, Appl. Opt., 38, 23582368, 1999b.

Müller, D., Mattis, I., Wandinger, U., Ansmann, A., Althausen, D., and Stohl, A.: Raman lidar observations of aged Siberian and Canadian forest fire smoke in the free troposphere over Germany in 2003: microphysical particle characterization, J. Geophys. Res., 110, D17201, doi:10.1029/2004JD005756, 2005.

Müller, D., Böckmann, C., Kolgotin, A., Schneidenbach, L., Chemyakin, E., Rosemann, J., Znak, P., and Romanov, A.: Microphysical particle properties derived from inversion algorithms developed in the framework of EARLINET, Atmos. Meas. Tech. Discuss., in preparation, 2016.

Nemuc, A., Vasilescu, J., Talianu, C., Belegante, L., and Nicolae, D.: Assessment of aerosol's mass concentrations from measured linear particle depolarization ratio (vertically resolved) and simulations, Atmos. Meas. Tech., 6, 3243-3255, doi:10.5194/amt-63243-2013, 2013.

Papayannis, A., Ancellet, G., Pelon, J., and Mégie, G.: Multiwavelength lidar for ozone measurements in the troposphere and the lower stratosphere, Appl. Opt., 29, 467-476, 1990.

Pappalardo, G., Amodeo, A., Pandolfi, M., Wandinger, U., Ansmann, A., Bösenberg, J., Matthias, V., Amiridis, V., De Tomasi, F., Frioud, M., Iarlori, M., Komguem, L., Papayannis, A., Rocadenbosch, F., and Wang, X.: Aerosol lidar intercomparison in the framework of the EARLINET project. 3. Ramanlidar algorithm for aerosol extinction, backscatter, and lidar ratio, Appl. Opt., 43, 5370-5385, 2004.

Pappalardo, G., Amodeo, A., Apituley, A., Comeron, A., Freudenthaler, V., Linné, H., Ansmann, A., Bösenberg, J., D’Amico, G., Mattis, I., Mona, L., Wandinger, U., Amiridis, V., AladosArboledas, L., Nicolae, D., and Wiegner, M.: EARLINET: towards an advanced sustainable European aerosol lidar network, Atmos. Meas. Tech., 7, 2389-2409, doi:10.5194/amt-7-23892014, 2014.

Sicard, M., D’Amico, G., Comerón, A., Mona, L., AladosArboledas, L., Amodeo, A., Baars, H., Baldasano, J. M., Belegante, L., Binietoglou, I., Bravo-Aranda, J. A., Fernández, A. J., Fréville, P., García-Vizcaíno, D., Giunta, A., Granados-Muñoz, M. J., Guerrero-Rascado, J. L., Hadjimitsis, D., Haefele, A., Hervo, M., Iarlori, M., Kokkalis, P., Lange, D., Mamouri, R. E., Mattis, I., Molero, F., Montoux, N., Muñoz, A., Muñoz Porcar, C., Navas-Guzmán, F., Nicolae, D., Nisantzi, A., Papagiannopoulos, N., Papayannis, A., Pereira, S., Preißler, J., Pujadas, M., Rizi, V., Rocadenbosch, F., Sellegri, K., Simeonov, V., Tsaknakis, G., Wagner, F., and Pappalardo, G.: EARLINET: potential operationality of a research network, Atmos. Meas. Tech., 8, 4587-4613, doi:10.5194/amt-8-4587-2015, 2015.

The EARLINET publishing group 2000-2010: EARLINET all observations (2000-2010), World Data Center for Climate (WDCC), available at: http://dx.doi.org/10.1594/WDCC/EN_ all_measurements_2000-2010 (last access: 9 November 2015), 2014 .

Voudouri, K., Siomos, N., Giannakaki, E., Amiridis, V., D’Amico, G., and Balis, D.: Comparison of Aerosol Backscatter and Extinction Profiles Based on the EARLINET Database and The Single Calculus chain for Thessaloniki Greece (2001-2014), in: Proceedings of 27th International Laser Radar Conference (ILRC), 5-10 July 2015, PS C1-27, New York, United States, 2-15, 2015.

Wandinger, U., Müller, D., Bockmann, C., Althausen, D., Matthias, V., Bosenberg, J., Weiß, V., Fiebig, M., Wendisch, M., Stohl, A., and Ansmann, A.: Optical and microphysical characterization of biomass-burning and industrial-pollution aerosols from multiwavelength lidar and aircraft measurements, J. Geophys. Res., 107, 8125, doi:10.1029/2000JD000202, 2002.

Wandinger, U., Freudenthaler, V., Baars, H., Amodeo, A., Engelmann, R., Mattis, I., Groß, S., Pappalardo, G., Giunta, A., D’Amico, G., Chaikovsky, A., Osipenko, F., Slesar, A., Nicolae, D., Belegante, L., Talianu, C., Serikov, I., Linné, H., Jansen, F., Apituley, A., Wilson, K. M., de Graaf, M., Trickl, T., Giehl, H., Adam, M., Comerón, A., Muñoz, C., Rocadenbosch, F., Sicard, M., Tomás, S., Lange, D., Kumar, D., Pujadas, M., Molero, F., Fernández, A. J., Alados-Arboledas, L., Bravo-Aranda, J. A., 
Navas-Guzmán, F., Guerrero-Rascado, J. L., Granados-Muñoz, M. J., Preißler, J., Wagner, F., Gausa, M., Grigorov, I., Stoyanov, D., Iarlori, M., Rizi, V., Spinelli, N., Boselli, A., Wang, X., Lo Feudo, T., Perrone, M. R., De Tomasi, F., and Burlizzi, P.: EARLINET instrument intercomparison campaigns: overview on strategy and results, Atmos. Meas. Tech. Discuss., 8, 1047310522, doi:10.5194/amtd-8-10473-2015, 2015.

Wang, Y., Sartelet, K. N., Bocquet, M., Chazette, P., Sicard, M., D’Amico, G., Léon, J. F., Alados-Arboledas, L., Amodeo, A., Augustin, P., Bach, J., Belegante, L., Binietoglou, I., Bush, X., Comerón, A., Delbarre, H., García-Vízcaino, D., GuerreroRascado, J. L., Hervo, M., Iarlori, M., Kokkalis, P., Lange, D., Molero, F., Montoux, N., Muñoz, A., Muñoz, C., Nicolae, D., Papayannis, A., Pappalardo, G., Preissler, J., Rizi, V., Rocadenbosch, F., Sellegri, K., Wagner, F., and Dulac, F.: Assimilation of lidar signals: application to aerosol forecasting in the western Mediterranean basin, Atmos. Chem. Phys., 14, 12031-12053, doi:10.5194/acp-14-12031-2014, 2014.
Whiteman, D. N., Melfi, S. H., and Ferrare, R. A.: Raman lidar system for the measurement of water vapor and aerosols in the Earth's atmosphere, Appl. Opt., 31, 3068-3082, 1992.

Winker, D. M., Hunt, W. H., and McGill, M. J.: Initial performance assessment of CALIOP, Geophys. Res. Lett., 34, L19803, doi:10.1029/2007GL030135, 2007. 